\title{
Factors Affecting the Success of Dental Implants
}

\author{
Carlos Nelson Elias \\ Instituto Militar de Engenharia, \\ Biomaterials Laboratory Rio de Janeiro, RJ, \\ Brazil
}

\section{Introduction}

Dental implants are fully placed in the bone in order to replace the natural root of the tooth and allow the installation of a dental prosthesis. The implant has gained importance with the work of Professor Per Ingvar Brånemark, who studied the microcirculation in bone tissue. Brånemark used stainless steel optical chambers to investigate the anatomy and physiology of tissue injury. The chamber was inserted in rabbit and dog legs. In some experiments the chamber structure of stainless steel was replaced by titanium. At the end of the experiments, Prof Brånemark observed that the titanium chamber was firmly attached to the bone (Brånemark et al., 1964). In fact, the titanium chamber could not remove from the surrounding bone once it had healed. Histological studies showed complete integration of titanium with the bone. After this chance observation, Brånemark developed a new concept of osseointegration which led to dental implants. The use of titanium-based dental implants in humans begun in 1965.

Dental implant technology was improved in recent years, providing patients with unparalleled levels of effectiveness, convenience, and affordability. This is one of the main reasons why so many dentists recommend dental implants as their preferred method to replace missing teeth. Titanium dental implants can offer many benefits. Because they present osseointegration with the jawbone, they are more stable than dentures. Patients with dental implants may be able to talk and eat more easily because they do not face the risk of their dentures dislodging. Dentures require replacement when the gum tissue shrinks and changes the fit; implants are not affected by this problem. The maintenance and hygiene of dental implants are easier than with dentures. Another reason for continued growth of the global market for dental implants is that dental implants offer an effective treatment for edentulism and because of the rising demand for cosmetic dentistry worldwide across all age groups.

The conventional clinical protocol proposed by Brånemark (Brånemark, 1990) for placement of dental implants involves two phases. The first is the placement of the implant in a surgical cavity prepared in the bone. The protocol recommends a healing period for tissue reorganization. The waiting time for healing to occur depends on bone quality and the region in which the implant was performed and was estimated by Brånemark as between 3 months to 6 months. The second phase of treatment is the prosthesis placement. With this technique, all natural teeth can be replaced, restoring function and aesthetics to the patient. 
The conventional protocol can be changed so that insertion of the implant and prosthesis placement can be made in a single step. In this case, the protocol is called immediately loading. The dentistry has an interest in reducing the healing time after surgery and loading the implants with oral forces safely. To meet this expectation one must consider that the body has a minimum time to perform the reactions that lead to osseointegration. In order to shorten the healing time, the strategy is to alter the biocompatibility of titanium implant surfaces, modifying the surgical technique and changing the implant design.

Despite the influence of the implant shape on the primary stability and the distribution of oral loads, there is no standardization of implant design. As shown in figure 1, there are dental implants on the market with different shapes. The cylindrical screw threaded implants are the most commonly used. Based on biomechanics and clinical observations, it was found that tapered implants have a higher compression capacity than cylindrical ones. During insertion the tapered implant induces compression stresses on the bone and increases the implant primary stability. However, the tapered implant is not suitable for all applications.

In an attempt to increase the success rate of implants, some researchers used the control of surface properties to select the type of cell that interact with the implant. It is known that osteoblastic cells adhere more quickly to rough surfaces of titanium than to smooth surfaces (Zhu et al., 2004; Puleo \& Bizios, 1992). Despite the advances in prosthodontic, the explanation of the influence of the implant surface on osseointegration remains incomplete. The new surfaces improve the success of implants in patients with low bone quality and quantity. However, there is still an unexplained loss of implants.

Several papers in the literature (Wennerberg, 1998; Tete et al., 2008; Suzuki et al. 2009; Stadlinger et al. 2008; Richards, 1996) describe the importance of titanium surface properties in implant osseointegration. These works studied the morphology, topography, roughness, chemical composition, surface energy, surface energy, surface composition, chemical potential, residual stress, the existence of impurities, thickness of titanium oxide film and the presence of metallic and nonmetallic compounds on the surface. The mentioned factors influence the concentration of cells involved in osseointegration. The importance of this work is the fact that by controlling the surface one can reduce the healing time of the implant and the bone-implant interface has enough mechanical strength to withstand the forces in the oral environment (Schucker et al., 2006).

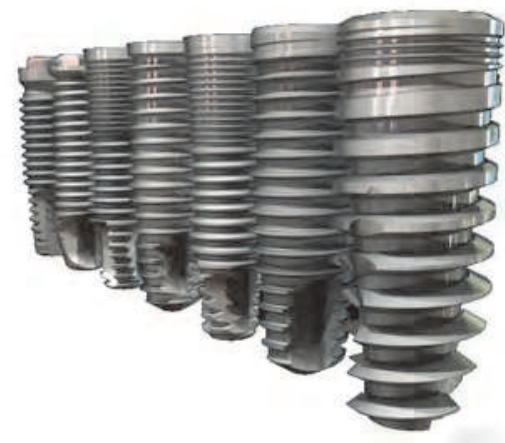

Fig. 1. Available dental implants with different design. (Courtesy of Conexão Sistemas e Prótese Company, Brazil). 
As discussed below in detail, besides biomechanics, the shape and dimensions of the implant, the quality and quantity of the bone, the surgical technique and the loading conditions (load intensity, direction of the forces involved) influence the stability of the implants and the maintenance of osseointegration.

\section{Biocompatibility}

The modern concept of biocompatibility involves, not only compatibility of the material with the tissue but its ability to perform a specific function. The response to specific individual materials could vary from one application site to another. Therefore, biocompatibility is defined only for a determined application. For example, the biomaterial used in intraocular lenses is not adequate for dental implants, although both show biological compatibility. In practice, there is no material that is biocompatible for all applications. Thus biocompatibility could not solely be dependent on the material properties (physical, chemical, mechanical) but also had to be defined by the situation in which the material is used (Williams, 2008).

The requirement for biocompatibility in a medical device intended for long term contact with the tissues of the human body is that the material does no harm to the tissues, and this presupposes chemical and biological inertness. However, in the case of dental implants, there is a need for osseointegration, which implies in a need for specific and direct interactions between biomaterials and tissue components.

The main factors influencing the biocompatibility of biomaterials are chemical composition, mechanical properties, electrical charge and surface features. The biocompatibility of materials used in dental implants is evaluated by studying the reaction between the implant and the bone. The reaction between the implant and the soft tissue is also important. The region where the implant is in contact with the soft tissue is responsible establishing a kind of seal that isolates implant and the bone from the mouth environment.

The analysis of the biocompatibility of biomaterials is accomplished by testing in vitro and complemented with tests in vivo. Tests in vitro involve cell culture, characterization of the chemical composition of surfaces, identification of the types of oxides and crystalline structures, determination of the thickness of the oxide layer, and quantification of resistance in mechanical loading conditions and dynamic resistance corrosion. The implant stability, surface roughness and surface wettability are also important.

The implant tests in vivo are done in animals, especially mice, rabbits, dogs, sheep and pigs. The last testing stage involves analysis of human clinical trials. In tests in vivo, after implant removal from the animal, the samples are analyzed by microscopy to determine the tissue quality around the implant. In such tests certain types of tissue reaction have been repeatedly observed. Another important test is the interface implant-bone mechanical resistance after osseointegration of the implant. This measurement is indirectly determined by measuring the minimum torque required to remove the implant.

Tests in vivo are done to evaluate the corrosion resistance and the breakdown between toxicity, hijacking (non-vascular tissue and thick in contact with the implant, the absence of pathological cells) and inertia (vascularized tissue and loose connective tissue). It is known that a relationship exists between the material toxic reaction and a high corrosion rate. Co, $\mathrm{Cu}, \mathrm{Ni}$ and $\mathrm{V}$ give rise to increased degradation in this order, and the degree of toxicity is increased in the same order. Metals that have corrosion passivation, i.e., high resistance to corrosion, do not trigger a negative response of tissues. This behavior is observed with $\mathrm{Pt}$, 
$\mathrm{Ta}, \mathrm{Nb}, \mathrm{Zr}$ and $\mathrm{Ti}$. It is possible to identify a correlation between biocompatibility, chemical stability and biological performance.

Corrosion resistance, degradation and the corrosion products released are important parameters for materials selection. Morais et al. (Morais et al., 2009) evaluated the concentration of $\mathrm{Ti}, \mathrm{Al}$, and $\mathrm{V}$ in rabbit tissues (kidney, liver, and lung) after 1 week, 4 weeks, and 12 weeks of placement in the tibiae of Ti-6Al-4V orthodontic mini-implants. Various amounts of $\mathrm{Ti}, \mathrm{Al}$, and $\mathrm{V}$ were detectable (figure 2), confirming diffusion of $\mathrm{Ti}, \mathrm{Al}$ and $\mathrm{V}$ from orthodontic mini-implants, with accumulation in remote organs (kidney, liver, and lung). Each metallic element had a different release behavior as a function of time. However, it is not enough to know which chemical elements are released; it is also important to analyze their influence on biocompatibility. Despite the tendency of metallic ion release with the $\mathrm{Ti}$ alloy, the measurable amounts of metals $(\mathrm{Ti}, \mathrm{Al}$, and $\mathrm{V}$ ) released from Ti-6Al-4V orthodontic mini-implants in rabbits' tissues were significantly below the average dietary intake of these elements through food and drink and did not reach toxic concentrations.

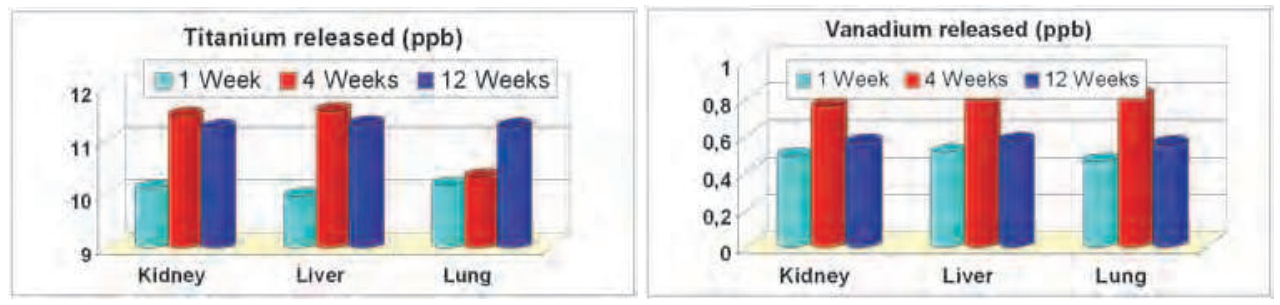

Fig. 2. Levels of metallic ions released from orthodontic Ti-6Al-4V mini-implants inserted in rabbits. (A) Ti (ppb). (B) V (ppb). Adapted from Morais et al. (Morais et al., 2009)

The analysis of biocompatibility becomes more complex when one considers that a low corrosion rate is not sufficient to ensure compatibility between the implant and the host tissue. Despite the fact that the corrosion resistance of stainless steel is about 300 times greater than that of $\mathrm{Mg}$, many steel alloys release nickel, that, depending on the patient, can be highly toxic. A similar behavior problem is observed in Cr-Co alloys (Williams, 2008). The amount of some chemicals that are released in the body is a determinant factor of material biocompatibility. There is evidence that there is correlation between the intrinsic toxicity of the ions and their ability to bind macromolecules. It is thus necessary to study the ability of the products of corrosion of metals to react with host proteins to form a potentially toxic metal-protein, and to analyze the stability of compounds formed during the release of corrosion products. A high corrosion resistance does not ensure biocompatibility; the tissue reaction depends on the concentration and toxicity of the corrosion products.

The materials that ensure osseointegration are $\mathrm{cp}$ titanium, tantalum and niobium. Most companies employ cp titanium. Implants made of $\mathrm{Ti}-6 \% \mathrm{Al}-4 \% \mathrm{~V}$ must be submitted to a surface treatment to exhibit osseointegration.

\section{Tissue and dental implant interactions}

Dental implants withstand oral loading because they have mechanical interlocking, fibroosseous retention and osseointegration. The mechanical retention is not dependent on the 
implant material. Dental implants are primarily anchored in bone by means of mechanical interlocking. For dental implants with a screw shape, axial loading is transmitted to the bone via threads. The factors that affect mechanical interlocking are associated to the implant shape, surface irregularities and roughness, holes and grooves, screw thread type and the number of threads.

The term "fibro-osseous retention" or "fibrointegration" is applied to cases where the implant is attached to the bone by connective tissue. The "fibrointegration" concept is that there is a soft tissue interface surrounding an implant or a dense collagen tissue between implant and bone, whereas the term osseointegration in optical microscopy analysis refers to the physical contact between new bone and the implant, without the interposition of connective tissue.

Osseointegration was defined as a phenomenon where intimate contact between bone and biomaterials occurs at the optical microscopy level, enabling surgical implants to replace loadbearing organs restoring their form and function (Albrektsson et al., 1981). In the case of osseointegrated implants, when there is no fibrous capsule, high resolution microscopic results shows an afibrillar interfacial zone at the bone-implant interface; mineralized tissue generally does not directly touch the biomaterial. The interfacial layer is rich in noncollagenous proteins as well as certain plasma proteins. Titanium-newbone interface presents a thin layer with proteoglycans and glycoproteins. Some researchers have suggested that this interfacial zone provides a mechanism for bonding between hard tissue and cp Ti (Dee, 2002a).

The cellular interactions at the surface of $\mathrm{cp}$ Ti implants occur through the weak forces of van der Waals and hydrogen bonds. The first exhibit a binding energy of only $10 \mathrm{kcal} / \mathrm{mol}$, due to molecular electric dipoles. The hydrogen bonds have energy of $1.10 \mathrm{kcal} / \mathrm{mol}$. The strong binding forces, both covalent and ionic, with a binding energy of 10-100 kcal/mol, depend on the microstructural characteristics of the surface at atomic scale. These connections occur at defects such as cations, anions and impurity atoms. The placement of dental implant results in blood leakage, homeostasis, and fibrin blood cot formation at the tissue-bone interface (Cooper, 2003). The first cells to appear on a biomaterial surface during blood contact (adsorption), coagulation, and fibrinolytic phases are blood cells, i.e., platelets, monocytes, and polymorphonuclear granulocytes followed by erythrocytes. Immediately after insertion of dental implants in the surgical alveolus, reactions occur with the host tissues.

Bioactive materials (glass ceramics and hydroxyapatite) induce specific biological reactions on the surface, resulting in the formation of a union between implant and host. These biomaterials form strong bonds with the adjacent tissue. They promote a connection with the bone tissue through bridges of calcium and phosphorus. Titanium does not fit into this classification because it has a titanium oxide layer, which is inert when in contact with the tissue. The micromechanism responsible for connection with the bone depends on specific surface chemical properties.

As Albrektsson et al. (Albrektsson et al., 1982) commercially pure (cp) titanium implants were shown to establish very close contacts with bone, without any interposed cellular layers. There was only a thin $(20-40 \mathrm{~nm})$ interfacial collagen-free layer of ground substance, i.e. macromolecules consisting of proteoglycans and glucose aminoglycans attached to a backbone of hyaluronic acid. Such observations, supported by other morphological and functional studies, indicated that $\mathrm{cp}$. titanium was excellently tolerated by the tissues. Johansson et al. (Johansson, 1990) examined the interface between bone and cp Ti implants and found a layer of proteoglycans about $20 \mathrm{~nm}$ thick and then, at a distance of about 100 $\mathrm{nm}$, heavily mineralized collagen fibers. Between the two layers, were identified fibrin and no organized mineral deposits. 
The oxidized surface of metals on an aqueous environment has a hydroxyl layer. Free metal ions can dissociate the water molecules and saturate or camouflage their positive charge with negatively charged hydroxyl ions. In the case of titanium oxide, for each dissociation of a molecule of water are produced two hydroxyl groups, which are differently positioned on the surface and produce an acid and a base in the neighboring area. These forms act as bipolar or amphoteric that can attract and bind with other molecules. An important feature of the amphoteric materials is the value of their point of zero charge measured by the $\mathrm{pH}$. At point zero, the positive and negative charges on the surface are balanced. The equilibrium point for the titanium oxide is a $\mathrm{pH}$ around 6.2. Some amino acids are bipolar and can react as acids (because of the carboxyl groups) or as bases (because of amino groups). These hybrids are ideal for chemical absorption and form a double bond with amphoteric hydroxylated titanium oxide.

Results of a study by Suzuki et al. (Suzuki et al., 2009) supports the suggestion that the implant surface treatment positively influenced the early bone healing, resulting in the presence of lamellar bone morphology due to primary remodeling in the woven bone/vascular rich network observed at the bone surrounding.

\section{Osseointegration}

It is well known that success in implant dentistry depends on several parameters that may improve considering both biologic and mechanical criteria. To explain the micromechanisms involved in osseointegration is necessary to know concepts of biology, physiology, anatomy, surgery and tissue regeneration. Osseointegration is observed in several areas, including not only dental implants, but also maxillofacial implants, replacement of damaged joints and placement of artificial limbs.

Osseointegration was defined by Brånemark as the direct connection of living bone with the surface of an implant subjected to a functional load. This definition has been modified over the years. Among the important requirements for osseointegration are the existence of a biocompatible surface, the presence of alveolar bone in the potential recipient sites and no traumatic surgery.

To Brånemark et al, the phenomenon of osseointegration is due to new bone formation in close contact with the implant. To achieve this end, protocols were developed, since several parameters have to be defined, from the choice of the metal to the placement and preservation of the prosthesis. Thus, osseointegration depends on the material used in the implant, the machining conditions, the surface finish, the type of bone that receives the implant, the surgical technique, design of the prosthesis and the patient care.

Among the surgical factors that influence osseointegration, implant bed preparation is of critical importance. Drilling the implant bed not only causes mechanical damage to the bone but also increases the temperature of the bone directly adjacent to the implant surface. Mechanical and thermal damage to the tissue surrounding the implant during drilling can have a destructive effect on the initial state of the cavity housing the implant (Anitua et al., 2007).

Necrosis occurs when the temperature exceeds $47 \mathrm{oC}^{\circ}$ for $1 \mathrm{~min}$. Therefore, care must be taken to avoid thermal bone injury during the procedure. External irrigation at room temperature can provide sufficient cooling during drilling and keep the temperature below the critical value of $47{ }^{\circ} \mathrm{C}$. Lower temperature saline was shown to be more effective in cooling the bone, and irrigation of the site should be continued between the drilling steps 
(Sener et al., 2009). Other factors affect heat generation during drilling, such as the drilling speed and force.

Bioactive materials bond to bone tissue through bridges of calcium and phosphorus. On the other hand, the chemical bond between non-coated titanium implants and living tissue occurs through weak van der Waals and hydrogen bonds.

The van der Waals forces (polarization and molecular electric dipoles) have bond energy of about $10 \mathrm{kcal} / \mathrm{mol}$. The hydrogen bonds have energy of $1.10 \mathrm{kcal} / \mathrm{mol}$. Covalent and ionic bonds have energy of the order of 10-100 kcal/mol. The types of connections between the implant and the body depend on the microstructural characteristics of the surface on atomic scale. These connections occur at defects such as cations, anions and impurity atoms. The chemical composition of oxide, density and grain boundary impurities exert great influence on the occurrence of strong bonds.

Osseointegration is a biological concept which involves the incorporation of a foreign body to the living bone (host) with fixation and stability when subjected to functional loads. In order for dental implant osseointegration to occur, there must be an adherence of the cells to the surface of the biomaterial. The implant surface characteristics can modulate the adsorption of proteins, lipids, sugar, and ions present in the tissue fluids. Attachment to a surface is a critical first step in cell response because it determine which cells will populate the surface and how many (Boyan et al., 2001). In vitro tests with osteoblastic cells showed that when cell adhesion occurs, the cells change shape and spread. In this phase, reorganization of cytoskeletal proteins occurs. At points of contact between cells and biomaterials there is an exchange of information between cells and the extracellular matrix, leading to activation of specific genes and remodeling. As the chemical composition of biomaterial induces different reactions of the cells, the surface properties of biomaterials induce different reaction mechanisms (Anselme \& Bigerelle, 2005). Both the morphology and the surface roughness of biomaterials influence proliferation, differentiation, extracellular matrix synthesis, production of local factors and even cell shape (Jayaraman et al., 2004)

The tests for implant removal by torsion indicate that there is a strong bond between the titanium implant and the bone. In the analysis of implants removed from animals it can be observed that there is a considerable amount of bone attached to the surface of the implant. This is an indication that osseointegration occurred.

Histologically, the identification of osseointegration is by the presence of regenerated bone at the implant-bone interface. The structure of the contact region can be analyzed in detail by means of electron microscopy and microanalysis. Histological preparations are suitable for this purpose. Several studies have found that there is a contact zone between implant and bone after placement. In these works it was possible to identify the presence of titanium atoms in the tissues surrounding the site of the alveoli. There was also the presence of lamellar bone with lacunae characteristics. Microanalysis and mapping of chemical elements in the region around the implant with microprobe indicated the presence of titanium, calcium and phosphorus. By this technique it is possible to verify that the relative intensities of $\mathrm{Ca}$ and $\mathrm{P}$ are constant, indicating that the bone is completely mineralized. Semiquantitative analysis in the region of the implant-bone interface shows the presence of chemical elements constituting the bone at a distance of $0.5 \mu \mathrm{m}$. These results show that the micromechanics of osseointegration is at the molecular level.

The tissue contact with the osseointegrated implant is the result of a process of new bone growth that involves continuous modeling and remodeling. Thus, it is important to 
understand that integration of bone with the implant is a dynamic process. The formation and stability of new bone about the implant is a combination of resorption and bone apposition. The balance between these processes is affected by various types of stimuli, including biomechanical forces in the dental prosthesis and the potential presence of inflammation (mucositis and peri-implantitis).

\section{Influence of movement on the osseointegration}

Despite the results obtained in studies to elucidate various aspects of osseointegration, there are doubts as to the actual micromechanisms involved in the formation of the union between bone and titanium, especially regarding the necessity of mechanical stimulation to induce bone connection.

After installation, the dental implants should provide initial mechanical stability to prevent movement. Movement between an implant surface and hard tissue causes fibrous capsule formation around the implant. Clinically, encapsulation is prevalent with stainless steel, alumina, zirconia and rarely seen with $\mathrm{cp}$ Ti implants without movement.

In fact, previous studies in animals reported a threshold of micromotion between 50 and 100 $\mathrm{mm}$, above which micromotion induces bone resorption at the interface, thus producing fibrosis around endosseous implants (Soballe et al., 1993; Szmukler-Moncler et al. 2000).

Implant stability depends on direct mechanical connection between implant surface and the surrounding bone and can be divided into primary, secondary and tertiary stability. The stability obtained immediately after insertion of a dental implant is called primary stability. The stability obtained after osseointegration is named secondary stability. The tertiary stability is the maintenance of osseointegration. Primary implant stability is considered to play an essential role in successful osseointegration. It depends on bone quality and quantity, implant geometry and the site preparation technique.

Primary implant stability can be remarkably decreased in "low quality bone" (Beer et al., 2003). There are no conclusive studies of the minimum primary stability that ensures osseointegration. Clinical results indicate that when the dental implant insertion torque is higher than 40 N.cm, the success rate increases. Implant insertion and prosthesis installation in the same surgery procedure is called immediate/early function of dental implants. Immediate loading is today a commonly used term in the dental field and indicates the possibility of applying an occlusal load to dental implants earlier than the traditional healing period of 3 to 6 months. However, the applied load is often reduced or even absent; therefore, it is more correct to use the term "immediate/early function" rather than "immediate/early loading." Moreover, the subdivision between "immediate function" (when the prosthesis is applied within hours from the implant insertion) and "early function" (when the prosthesis is applied earlier than the traditional period of 3 to 6 months) has been accepted (Bogaerde et al., 2010).

\section{Importance of titanium oxide layer in osseointegration}

Although titanium is used extensively in the manufacture of dental implants since the early 1970 's, there are still doubts about the mechanisms involved in its biological response.

Titanium spontaneously forms a very thin oxide film on its surface. This passive film protects titanium against corrosion attack or degradation in a wide range of harsh or aggressive environmental conditions. The biocompatibility of titanium as an implant 
material is attributed to surface oxides spontaneously formed in air and/or physiological fluids (Williams, 1981).

During machining of titanium, absorption of $\mathrm{O}_{2}$ molecules occurs. After about 10 nanoseconds, the molecules dissociate and a monolayer of atomic oxygen is deposited. This oxygen reacts with titanium to form a titanium oxide film with a thickness between 50 and $100 \AA$ (5 a $10 \mathrm{~nm})$. This film, which forms spontaneously at ambient temperature and pressure, is called native oxide. Titanium oxide films can also be artificially grown by heating, acid etching and electrolytic oxidation also known as anodizing.

Titanium oxide films with thicknesses up to $800 \mathrm{~nm}$ can be formed by anodizing. At the body $\mathrm{pH}$, the stable form of titanium oxide is $\mathrm{TiO}_{2}$. After the implant has remained in place for some time, its surface becomes covered with plasma protein, especially fibronectin and vitronectin.

Some researchers studied the titanium oxide films on dental implant surfaces, measuring properties such as the crystalline structure, composition and thickness of the film. These studies showed that healing around titanium implants occurs through a gradual process of mineralization, i.e., osseointegration involves mechanisms that do not start at the implant surface (Larsson et al., 1996). Moreover, during healing, which occurs in a few days and remodeling, which requires weeks or even years, the biological processes that occur at the interface affect the properties of the initial oxide layer. The thickness of the oxide layer increases with time and incorporates ions of $\mathrm{Ca}, \mathrm{P}$ and $\mathrm{S}$ from the physiological environment. The surface properties of implants, such as morphology, roughness, thickness of the oxide layer, impurity level and types of oxide depend on the treatment to which the material was submitted. These surface properties have a significant effect on new bone formation.

After machining and cleaning, commercial dental implants are submitted to a surface treatment in order to attain the desired roughness and an adequate thickness of the titanium oxide film. It is important to remember that contact between the implant and the body established through a titanium oxide film; there is no contact between metallic titanium and the body.

The main difficulty for studying the influence of titanium oxide on osseointegration lies in isolating the variables that characterize the surface and analyze then one at a time. For instance, in a specific study it is necessary to change only the type of oxide layer (crystalline structure) while maintaining the same roughness and thickness; in a second study, it is necessary to change only the roughness and so on.

Larsson et al. (Larsson et al., 1996) investigated the bone formation around titanium implants with varied surface morphologies (machined, electropolished and electropolished followed by anodizing). The results showed that after one week a thin layer of bone covered with osteoid from the endosteum has been observed around the implants. After seven weeks the amount of bone around electropolished implant surfaces is lower than for anodized and machined machined implants with grooves between 1 and $10 \mu \mathrm{m}$. Anodic oxidation of the electropolished surfaces, which produced areas of increased roughness and a thicker surface oxide, had an enhancing effect on the rate of bone formation. Electropolished implants have less bone formation around the implant due to a lower surface roughness and the presence of a thin oxide layer. This behavior can be attributed to the fact that osteoblast cells adhere and spread more easily on rough surfaces than on smooth ones. They concluded that both surface topography on the submicrometer scale and oxide thickness influence the bone response to titanium.

Since host cells interact with adsorbed proteins and not with the material itself, the types and states of adsorbed proteins are critical determinants of cells responses to implanted 
biomaterials. Albumin, fibrinogen and immunoglobulin predominate on many blood and tissue contact biomaterial (Tang \& Hu, 2005). But blood has over 150 proteins. On the basis of mass transport considerations, more abundant proteins and proteins with the highest diffusion coefficient will be first to arrive at the surface. The most abundant proteins are albumin $(40 \mathrm{mg} / \mathrm{mL}), \operatorname{IgG}\left(15(\mathrm{mg} / \mathrm{mL}), a_{1}\right.$-Antitrypsin $(3 \mathrm{mg} / \mathrm{mL})$, fibrinonogen (3 $\mathrm{mg} / \mathrm{mL})$. Because of its highest concentration and diffusion coefficient $\left(6.1 \times 10^{-7} \mathrm{~cm}^{2} / \mathrm{s}\right)$, albumin dominates initial interaction with surface. Fibrinogen can dominate the surface because of greater affinity, even though its rate of arrival is more than 100 times less than that of albumin (Dee et al., 2002b).

In the past, implants coated with hydroxyapatite (HA) were widely used. They are no longer used due to the huge number of periimplantitis observed. However, HA-coated implants had a larger amount of bone overlying the surface compared to uncoated implants. In these implants the number of gaps between the HA coating and bone was lower and the formation of mineralized nodules was more pronounced.

\section{Interaction of cells with the biomaterial surface}

Any material placed in the body will cause a biological response, and the implants interact with the body environment through their surface. Consequently, the study of the properties of the outmost layer of a dental implant is critically important in the analysis of both the biological response to the implant and the titanium responses to the physiological environment.

With insertion of the biomaterial in the human body and contact with the material with the body fluids $(\mathrm{BF})$, multiple events are triggered. In the past, it was believed that identification of a foreign body by the cells led to defensive strategies and inflammatory reactions that resulted in encapsulation of the biomaterial to isolate it from the body. Currently, it is known that through material selection, processing and surface coating, it is possible to obtain the desired cell response. One can favor the adsorption and absorption of a specific type of cell or even prevent the adhesion of organic material. For example, the surface of coronary stents must have properties that prevent cell adhesion. Moreover, the surface of dental implants must allow the adsorption of specific proteins to trigger the mechanisms involved in osseointegration.

As soon as an implant is inserted, adsorption of cells on the surface of the foreign body begins. The cells activate mechanisms to identify the chemical composition of the material and induce different reactions. Cell react differently to bioinert, bioactive and bioreactive materials (Wolner et al., 2006). In the case of bioinert materials (stainless steel, Co-Cr alloy, zirconia, alumina, nylon, etc.) the body induces the formation of a capsule of fibrous tissue surrounding the biomaterial. Bioactive materials (titanium, niobium and tantalum), on the other hand, induce mechanisms that lead to osseointegration. For bioreative biomaterials (hydroxyapatite, calcium phosphate, bioglass), ionic changes occur in the body and the biomaterial is resorbed.

When a bioactive implant is inserted into bone, its surface is modified by ions and proteins. The increased surface energy may alter plasma proteins adsorbed to the surface and activate cell membrane receptors. The process of coagulation is triggered and platelet activation initiates an inflammatory response by recruiting neutrophils and monocytes to the wound area. Platelet-derived cytokines such as IGF, TGF- $B$ and PDGF enhance the osteogenic response and bone formation by stimulating the migration and proliferation of osteogenic 
cells, which differentiate into osteoblasts and eventually produce bone matrix. Thus, the cascade of events induced by the activation of platelets, including the release of chemotactic and mitogenic factors, increased production of thrombin and the recruitment and activation of neutrophils and monocytes may explain the faster bone repair around surfaces of different chemical composition (Togashi et al., 2007; Kikuchia, 2005).

New technologies and new materials have emerged based on these concepts (Kashiwagi et al., 2009; Li et al., 2008). The new biomaterials are developed with the aim of presenting biocompatibility for a specific application. Unfortunately, sometimes the foreign material inserted into the human body does not induce the desire response. In some cases, the physiological reactions are deleterious. Better understanding and control of material properties can eliminate or minimize the critical reactions and allow the advancement of technology of biomaterials. One of the critical responses to foreign materials is directly related to the interaction between the material surface and adsorption proteins (Le Duc \& Wang, 2006).

In the body fluid (BF) there are ions in solution as well as lipids, carbohydrates and proteins that can be adsorbed on the biomaterial surface. The biomaterials are selected to obtain a specific response necessary for certain applications (Niinomi, 2002). In this process, proteins play an important role to induce the desired response.

After the initial reaction of proteins with the foreign body a physiological response occur, following by a sequence of events leading to acceptance or rejection of the material. These responses involve the recruitment of several cell types that are present at the interface of the material and perform activities such as extracelular matrix remodeling (Thull, 2002). In the case of dental implants, recruitment of cells, that leads to implant encapsulation, is not desirable. Proper implant surface preparation, adequate loading conditions and control of micromovements are essential and decisive to avoid formation of fibrous tissue in the boneimplant interface. The use of commercially pure titanium is no guarantee of osseointegration. Based on the concepts presented, it is concluded that the surface properties of implants are extremely important for controlling the reactions that lead to improved performance and osseointegration of the implant. Among the properties of the implant surface that influence the attraction, repulsion, adsorption and absorption of proteins and cells as well as on osseointegration are roughness, wettability, electrical charge, chemical composition, surface energy, residual stresses and morphology.

The wettability of a liquid is defined as the contact angle between droplets of the liquid in thermal equilibrium on a horizontal surface. Depending on the type of surface and liquid the droplet may take a variety of shapes as illustrated in figure 3 . The wetting angle $\theta$ is given by the angle between the interface of the droplet and the horizontal surface. The liquid is seemed wetting when $90<\theta<180$ degrees and non-wetting when $0<\theta<90$. When $\theta=180$ degrees corresponds to perfect wetting and the drop spreads forming a film on the surface. Figure 4 shows hydrophilic dental implant surface.
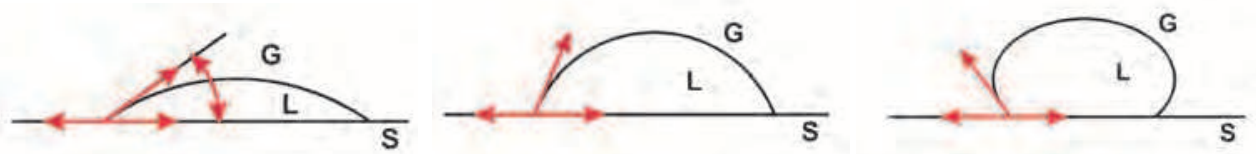

Fig. 3. Wetting ability of material surface. Hydrophilic surface (left), normal hydrophilic surface (middle) and hydrophobic surface (right). 
Cell adhesion involves short term events such as physicochemical linkages between cells and substrates and long term events leading to the regulation of cell expression involving extracellular proteins, cell membrane proteins and cytoskeleton proteins (Anselme, 2000). The chemical composition and microstructure of a surface can regulate the adsorption of components present in the extracellular fluid. It is known that rough and chemically activated surfaces provide the ideal conditions for direct protein adsorption and alter the adsorption of fibronectin and albumin due to modifications in their ionic state. These mechanisms are important for implant osseointegration.

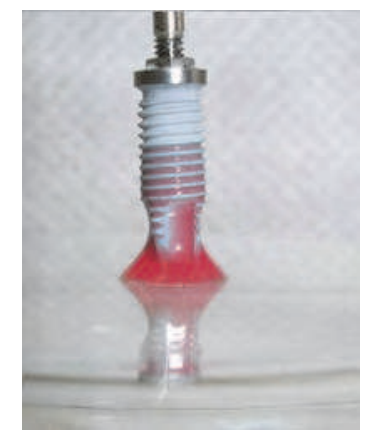

Fig. 4. Vulcano Actives ${ }^{\mathrm{TM}}$ dental implant showing its high hydrophilic surface.

Adhesion is a basic cellular process that directly influences cell growth, differentiation and migration, as well as morphogenesis and healing. The extracellular matrix (ECM) elaborated by cells constitutes a regulator of cell adhesion and differentiation and contributes to the mechanical properties of the tissue. These regulatory effects of ECM are mediated through transmembrane proteins specialized in cell substrate adhesion. These cell surface receptors are called integrins, which are $\alpha \beta$ heterodimeric proteins. The $\alpha \beta$ association is essential for integrins to bind to their ligand and determines the specific ligand binding (a ligand is an ion or molecule that binds to a central metal atom to form a coordination complex. The bonding between metal and ligand generally involves formal donation of one or more of the ligand electron pairs. The nature of metal-ligand bonding can range from covalent to ionic). Some integrins are able to bind several ligands, $a 3 \beta 1$ is a laminin, collagen, fibronectin, and, enctatin receptor (Verrier et al., 2002). All these mechanisms depend on the surface properties of the biomaterial.

The arrangement of atoms in the surface of metals is different from the atomic arrangement in the bulk and makes is more receptive to adsorption of atoms and molecules from the environment. The reactions between the environment and the biomaterial surface increases when the energy per unit area at the metal surface increases.

Titanium, having a high energy surface, will easily adsorb $\mathrm{O}_{2}$ molecules, which dissociate and form titanium oxide in a few milliseconds. Therefore, even in the implants without surface treatment, there is no body contact with metallic titanium, but only with a layer of titanium oxide. Therefore, for the biocompatibility of commercially pure Ti implants, the properties of the oxide layer are more important than those of the metal.

The thickness of the protein coating on the surface of the implants depends on the surface energy of the material. Histological observations made on implants with high surface energy indicated that they have layers of proteins with greater thickness than those with 
low energy, revealing that cellular activity varies with the surface energy. When implants with low surface energy were mechanically separated from the capsule tissue and inspected under a microscope, it was found that most of the surface did not have tissue. In implants with low surface energy, the cells remain with an almost spherical shape, lose their attachment and can easily be separated from one another. The globular appearance of these cells allowed identifying them histological as fibroblasts. The globular appearance of the cells is associated with poor cell growth, but is not related to the normal activity of fibroblasts in the healing process.

In order to study the biocompatibility of materials and the extent of osseointegration, one needs quantitative and qualitative information on the surface energy of the implants, since it affects the interactions between biomaterial surfaces with proteins, cells and bacteria. Different cell types use different mechanisms when attaching to different surfaces and, as a rule, cells do not interact with the surface directly, but via proteins secreted by the cells and adsorbed by the surface, forming a distinct layer. Adhesive compounds such as fibronectin and vitronectin are present in the serum adsorbed on the substrate and adhesion is in fact an interaction with these compounds. This interaction is of the type ligand-receptor because the cells have specialized receptors (integrins) through which they identify the adsorbed adhesive proteinsligands. Guided by the substrate surface properties, conformational alterations of the adsorbed proteins possibly change their biological behavior. In this context, the initial cellular interactions depend on surface physicochemical properties such as wettability, charge, heterogeneity, topography, roughness and the presence of functional groups (Vladkova, 2010) The direct biochemical interactions between the surface of titanium implants and tissue molecules are short range; the predominant type of chemical bonds is the weak forces of van der Waals and hydrogen bonds such as polarization and molecular electric dipoles. The surface energy is directly proportional to the tendency to adsorb molecules. The general rule is that materials with a surface tension between 20 and 30 dynes $/ \mathrm{cm}^{2}$ exhibit a low adsorption. Materials with surface tension values above this range are more adsorptive.

The sessile drop technique is a method used for the characterization of solid surface energies, and in some cases, aspects of liquid surface energies. The main premise of the method is that by placing a droplet of liquid with a known surface energy, the shape of the drop, specifically the contact angle (figure 3), and the known surface energy of the liquid are the parameters which can be used to calculate the surface energy of the solid sample.

The Owens/Wendt theory (Owens et al., 1969) divides the surface energy into two components: surface energy due to dispersive interactions and surface energy due to polar interactions. The no dispersive or polar component arises from electrostatic interactions, metallic bonding forces, hydrogen bonding and dipole interactions. The dispersive or no polar component has its origin in interactions between molecules and covalent bonds. These two components can be calculated as $t$ he ratio of the contact angles with surfaces with known properties and the contact angles with the surface under investigation.

There is a relationship between critical surface tension and biocompatibility. The surface energy model includes contributions from the solid phase (implant) and the liquid phase (blood) to the physiological results. The basic premise is that the driving force for protein adsorption is the surface free energy. Thus, proteins are not strongly absorbed in a surface with low interfacial free energy and remain in solution. In the case of dental implants, the properties of the liquid phase can be changed by drugs to activate tissue mechanisms that facilitate adherence. The use of drugs and an adequate preparation of the implant surface are seen as complementary methods to improve osseointegration. 
Materials with a high surface energy adsorb macromolecules more easily, have a higher number of favorable sites for cell adhesion, and facilitate the growth of layers that stimulate cell binding. In order to improve osseointegration, it is desirable that the strength of the nondispersive component of the surface tension be as low as possible, while the dispersive component remains high.

\section{Types of dental implants}

There is not a consensus among researchers as to the best surface roughness and even the shape of the implants. As shown in figure 1, there are a number of types of dental implants available. The same manufacturer produces implants with different shapes and surfaces. It is common knowledge that the geometric shape of the implant should be chosen in such a way to provide the largest bone-implant contact area in order to improve osseointegration decrease the stress concentration close to cervical area.

Commercial dental implants can be divided into groups according to shape, type of connection to the prosthetic component, surface treatment and roughness.

a. Shape (figure 5): cylindrical, conical, hybrid;

b. Type of connection (figure 6): external hexagon, internal hexagon, Morse taper, dodecagon;

c. Surface treatment (figure 7): acid etching, sandblasting, anodizing, coated by plasma sprays, nanoparticles deposition, laser treatment,

d. Surface roughness: macroroughness (figure 7D and 6E), microroughness (figure 7A), nanoroughness

In an attempt to improve the interaction between bone and implant, increase the surface area, improve the distribution of forces to the bone and achieve a better primary stability, various implants shapes were developed. Screw-shaped dental implants dominate the dentistry market. The screw shape provides a large contact area between implant and bone, increases primary stability, reduces the shear stress in the bone-implant interface, reduces the stress concentration in the cervical region and relieves stress concentration. The thread profile is characterized by the depth, pitch, flank angle, the top radius of curvature, and the straight part at the bottom of the thread. The rounded thread top relieves stress concentration and reduces the stress on the bone. However, there is no recommendation or standardization for the screw of dental implants. During bone repair, it is important that implant micromotions do not submit the tissues to any kind of trauma. Destabilization of the bone-implant interface leads to the interposition of fibrous tissue on its surface and prevents osseointegration.

Implants with large thread steps increase bone-implant interface shear stresses which should be avoided because bones have a lower strength to shear than to tension and compression.

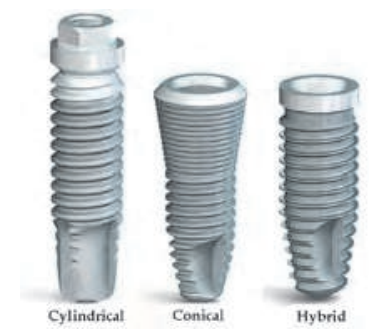

Fig. 5. Dental implants design. (Courtesy of Conexão Sistemas e Prótese, Brazil). 


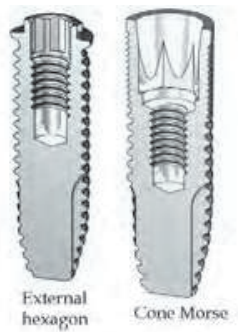

Fig. 6. Dental implant with external hexagon and internal Morse taper. (Courtesy of Conexão Sistemas e Prótese)

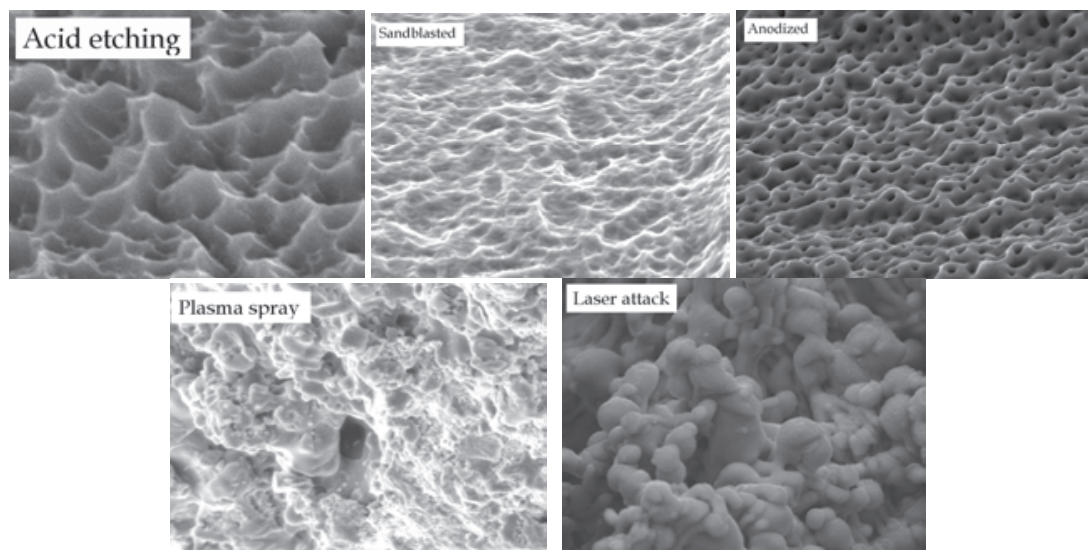

Fig. 7. Surface morphologies of available titanium dental implant. (A) Acid etching. (B) Sandblasting. (C) Anodizing. (D) Coated with $\mathrm{TiO}_{2}$ by plasma spray. (E) Laser treatment.

By varying the profile of fillets of tapered threads is possible to increase the surface area of the conical implant relative to cylindrical implants with the same diameter and length (table 1). Implant thread fillets are not standardized. The fillet can be triangular, square, V-shaped, rounded or trapezoidal (figure 8).

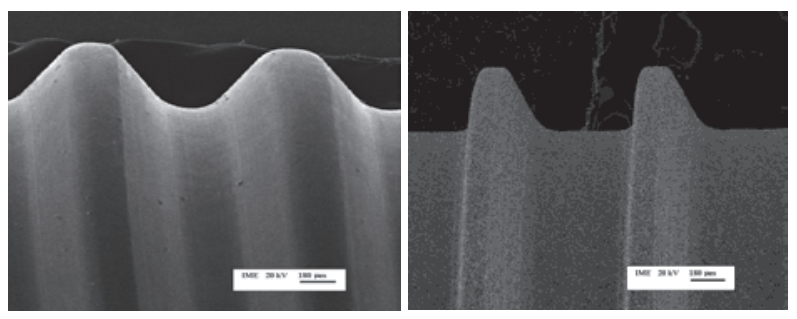

Fig. 8. Profiles of fillets. Cylindrical implant (left) and conical implant (right).

Initially, prostheses were composed of seven parts: implant, intermediate, intermediate screw, abutment, abutment screw, bolt retainer and prosthesis. However, clinical experience has shown that the larger the number of components, the greater the possibility of failure. 
Currently, cemented prostheses are composed of four elements: implant, abutment, abutment screw fixation and prosthetic crown. Screwed prostheses are made of implant, abutment, abutment screw, crown and screw crown. These sets require a strict control of manufacturing and design to ensure that the chewing forces are properly transferred to the host. There is an apparent lack of consensus as to the implant shape that provides the best performance. For some, the choice of a threaded cylindrical implant takes into account the prevalence of compressive stresses in relation to shear; the choice of a cylindrical implant maximizes the importance of maximum resistance to shear stress.

\begin{tabular}{|c|c|c|}
\hline Length $\mathbf{( m m )}$ & Cylindrical & Conical \\
\hline 8.5 & 217.57 & - \\
\hline 10.0 & 252.55 & 283.69 \\
\hline 11.5 & 283.52 & 311.76 \\
\hline 13.0 & 316.92 & 343.44 \\
\hline 15 & 360.18 & 383.51 \\
\hline
\end{tabular}

Table 1. Influence of dental implant design on the surface area. Implant diameter equal to $5.0 \mathrm{~mm}$.

With respect to length and diameter, the implants are marketed with different dimensions, in order to take into account different clinical treatment. Dental implants with cylindrical threads are commercially available with diameters between 3.25 and $6.0 \mathrm{~mm}$ and lengths between 5 and $18 \mathrm{~mm}$. For implants with similar surface treatments, the larger the size, the greater the resistance to removal of the implant after osseointegration. The choice of implant size is determined by the available space, bone quality and implant bed. Based on the characteristics and volume of available bone in the region of surgery, the professional defines the type, shape and size of the implant to be used.

Among the different parts of the implants, the dimensions of the cervical region deserve the most attention. About $12 \%$ of connections show loosening of the abutment screw during the first year of use due to lack of stability. To minimize this problem, many implants are designed with an external or internal hexagon. However, only changes in the design of implants are not sufficient to eliminate the problem; one must examine the dimensional tolerances of the implants, the interchangeability of parts and the couplings between parts. Binon (Binon, 1998) found that the lack of fit between implant and prosthesis causes instability of the joints connecting the system. In other words, a difference between the dimensions of the implant hexagon and hexagon connection impairs the system stability Therefore, one should take special attention to dimensional tolerances of the implants and connections, which depend on factors related to part manufacturing, surgery planning and execution and the implant quality.

\section{Roughness}

The importance of implant surface topography for successful osseointegration was first pointed out by Albrektsson et al. (Albrektsson et al., 1981). More recent studies have confirmed that the surface roughness of implants affects osseointegration and the mechanical stability of dental implants (Werner et al., 2009; Zhu et al., 2004; Puleo, 1992; 
Wennerberg et al., 1998a). Several mechanisms involved in osseointegration depend on surface morphology, since the cells react differently in contact with smooth surfaces and rough surfaces. Fibroblasts and epithelial cells adhere more strongly to smooth surfaces and the ability of osteoblast proliferation and collagen synthesis is greater in surface with moderate roughness (Wennerberg et al., 1998b; Cochran et al., 1998). Despite the importance of roughness in osseointegration, there is no standard for the roughness of dental implants. The surface of dental implants is greatly influenced by the action of the cutting tool. Elements such as tool shape, speed, feed, and cutting fluid can be varied to affect the surface topography. Other factors affecting the surface are the instability of the cutting tool due to chatter or imbalance in the grinding wheel, and errors in the machine tool guideway (Morton, 1994).

Machined dental implants have a pattern of grooves from the manufacturing process that can be detrimental for osseointegration (figure 9). To improve osseointegration it is important that the surface treatment creates the right kind of defects. Depending on size, surface topography can be defined in terms of surface roughness, waviness and form (Figure 10). For dental implants, roughness is the most important feature.

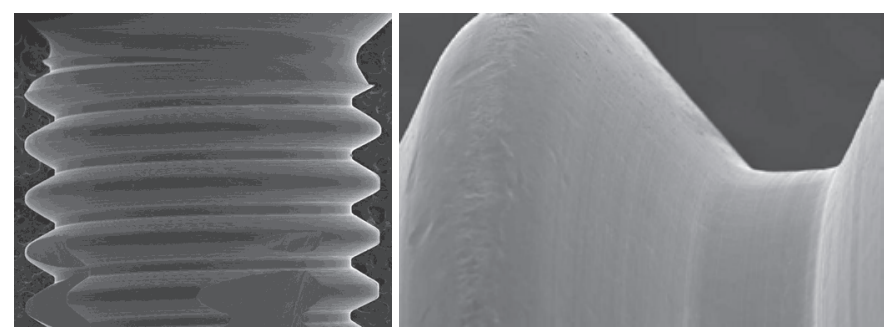

Fig. 9. Surface morphology of machined dental implant, showing the grooves left by the manufacturing tools.
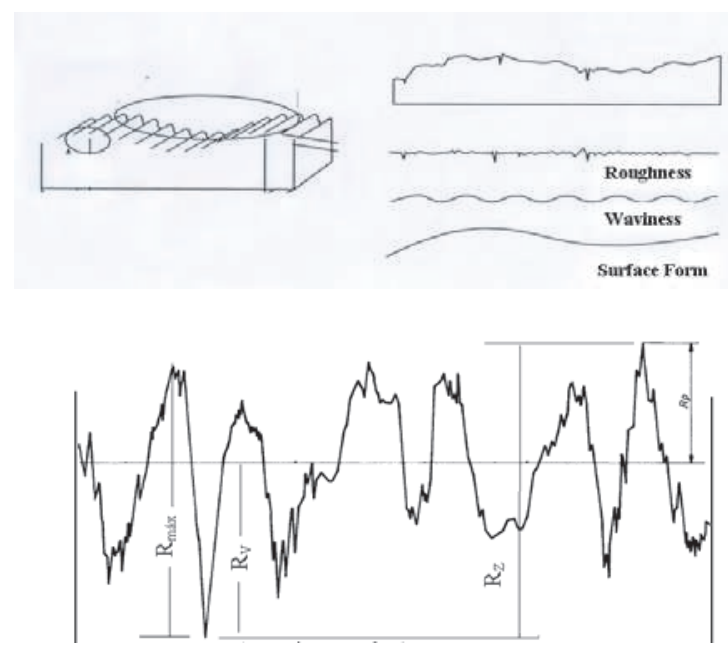

Fig. 10. Sketch representing the surface topography and roughness parameters. 
Surface roughness is the primary component of texture and refers to high frequency irregularities. In the case of dental implants, surface roughness consists of fine imperfections on the order of micrometer $(\mu \mathrm{m})$ due to the cutting process (figure 9) or due to a surface treatment (figure 7). In machined implants, roughness is closely related to the cutting tool and consists of a regular pattern of shallow grooves.

Surface waviness refers to the secondary component of texture upon which roughness is superimposed. It is as a series of regular deviations of approximately sinusoidal shape and a size on the order of millimeters. It is attributed to the deformations and vibrations of the machine and the part during manufacturing.

Surface form is some irregularity the general shape of the surface, neglecting roughness and waviness, which is frequently caused by errors in the machine tool guideway and deformations due to stress patterns in the component.

Since the basic types of surface geometry are caused by different factors and tend to have different relationships to the performance of the component, it is usual to consider them separately during analysis. In general, if control of dental implant performance related to surface topography is required, roughness is main parameter to be analyzed.

For effective analysis of surface roughness, the profile is evaluated according to internationally recognized mathematical formulas called parameters (ISO 468: Surface roughness parameters. ISO 4287: Surface texture: Profile method, terms, definitions and surface texture parameters. ISO 4288: Surface texture: Profile method, rules and procedures for the assessment of surface texture. ISO 8785: Surface imperfections, terms, definitions and parameters. BS 1134-1: Assessment of surface texture, methods and instrumentation. BS EN ISO 3274: Geometric product specifications (GPS). Surface texture and profile method. ASME B46.1: Surface texture: surface roughness, waviness, and lay). The purpose of using a parameter is to resort to a number that can characterize a certain aspect of the surface and hence eliminate the need for subjective operator assessment. Since it is not possible to characterize a surface completely with a single parameter, a combination of parameters is normally used.

Despite the importance of surface roughness on osseointegration of dental implants, there are no standards to measure the roughness of the implants. The procedure adopted has been to adopt the same parameters used in engineering. Moreover, previous studies of the subject (Wennerberg 1996; Elias et al., 2008) analyze only a few parameters and offer no conclusive explanation of the influence of each roughness parameter on osseointegration.

Roughness measurements are performed using mechanical or electronic devices, such as a style instrument called profiler. The use of a contact roughness meter (mechanical) has several limitations, including the fact that the values of peak heights and depths of valleys are limited by the tip shape. The most common non-contact technique uses a laser beam. It is also possible to evaluate the surface roughness by atomic force microscopy; however, this technique is limited to a small region of the specimen.

Surface roughness is characterized by small protrusions (peaks) and holes (valleys) on the surface in relation to a reference plane. The parameters used to quantify this roughness are determined in two dimensions (2D) or three-dimensional (3D). The letter " $R$ " is used for parameters related to roughness and the letter "S" for parameters related to the surface profile. The measured parameters can be divided into three groups:

a. Spaciousness parameters are measures of the height of the irregularities or vertical deviations on the surface. They are determined by the peak heights and depths of 
valleys, or both, regardless of the spacing between the irregularities along the surface $\left(R_{a}, R_{\mathrm{q}}, R_{\mathrm{z}}, \mathrm{R}_{\mathrm{sk}}, \mathrm{R}_{\mathrm{ku}}, \mathrm{R}_{\mathrm{t}}, \mathrm{S}_{\mathrm{a}}, \mathrm{S}_{\mathrm{q}}, \mathrm{S}_{\mathrm{z}}, \mathrm{S}_{\mathrm{sk}}, \mathrm{S}_{\mathrm{ku}}, \mathrm{S}_{\mathrm{t}}, \mathrm{R}_{\mathrm{p}}, \mathrm{R}_{\mathrm{v}}, \mathrm{R}_{\mathrm{c}}, \mathrm{R}_{\mathrm{m}}\right)$.

b. Spacing parameters are determined by the distance between irregularities along the surface (Sm and Scx)

c. Hybrid parameters describe a combination of the amplitude and spacing of surface irregularities $\left(\mathrm{S}_{\mathrm{qd}}\right.$ and $\left.\mathrm{S}_{\mathrm{dr}}\right)$.

Roughness average $\left(R_{a}\right)$, the most common1y used roughness parameter, is defined as the mean height of the roughness profile. Its main drawback is the fact that different profiles may have the same $\mathrm{Ra}$ and differ significantly in performance. Another averaging parameter, $\mathrm{R}_{\mathrm{q}}$, defined as the root mean square of the roughness profile, is more sensitive to surface variations. After a surface treatment of the implant, it may be more adequate to specify the maximum roughness height, $R_{\max }$, or the peak-to-valley height, $R_{z}$, rather than use the mean height given by $R_{a}$. The $R_{\max }$ parameter measures the highest and lowest points of the profile. There are doubts as to whether the variations in the heights of surface irregularities are more important than the distance between them, or what the best combination of these factors for osseointegration is.

The definitions of the main roughness parameter are:

- $\quad R_{a}$ (average roughness): $R_{a}$ is average value of the amplitudes in relation to a reference line. This parameter quantifies the average vertical distance between the five highest peaks and five major valleys.

- $\quad R_{q}$ or $R_{m s}$ (root mean square roughness): $R_{q}$ is the square root of the squares of the amplitudes in relation to the midline. The squaring of the values of irregularity increases the effect of the irregularities that deviate markedly from the average.

- $\quad R_{z}$ (average partial roughness): $R_{z}$ is the arithmetic mean of five values of the partial roughness $Z_{i}$. The partial roughness $Z_{i}$ is defined as the sum of the absolute values of the ordinates of the points of greatest deviations (above and below the midline) existing within a sampling length. Graphically, this represents the height between the maximum and minimum points of the profile within the sampling length.

- $\mathrm{R}_{\max }$ (maximum roughness). $\mathrm{R}_{\max }$ is the largest value of partial roughness $Z_{\mathrm{i}}$ along the measurement path. Another parameter similar to $R_{\max }$ for measuring surface roughness is $R_{y}$, defined as the maximum distance between the highest peak and the largest valley within the sampling length.

- $\quad \mathrm{R}_{\mathrm{t}}$ (total depth). $\mathrm{R}_{\mathrm{t}}$ is the vertical distance between highest peak and the deepest valley.

- $R_{3 z}$ (average roughness of the third peak). In each module are plotted the distances between the third highest peak and the third deepest valley. $R_{3 z}$ is the height of this peak plus the depth of the valley.

Other amplitude parameters are:

- $\quad \mathrm{R}_{\mathrm{sk}}$ : asymmetry factor (skewness);

- $\quad \mathrm{R}_{\mathrm{ku}}$ : flattening profile (kurtosis);

- $\mathrm{R}_{\mathrm{p}}$ or $\mathrm{Z}_{\mathrm{p}}$ : maximum height of the highest peak of surface roughness, situated above the midline.

- $\quad \mathrm{R}_{\mathrm{v}}$ or $\mathrm{Z}_{\mathrm{v}}$ : depth profile of the largest valley

- $\mathrm{R}_{\mathrm{c}}$ : average height of the profile elements

- $\mathrm{R}_{\mathrm{om}}$ : depth of the deepest valley

- $\mathrm{S}_{\mathrm{m}}$ : mean distance between furrows or average distance between peaks

- $\mathrm{R}_{\mathrm{Sm}}$ : average width of the profile elements 
- $\quad$ PC: number of peaks per unit length

The mean values of some roughness parameters for a titanium surface are displayed in Table 1. After surface treatment, significant changes are observed in the roughness parameters that affect the cell-surface interaction, as measured by implant removal torque. Multiple comparisons Tukey's HSD tests have shown a statistically significant difference in $\mathrm{R}_{\mathrm{a}}$ after surface treatment. The machined surface has grooves, which increase roughness. The surface area ( $\mathrm{A}_{1}$ and $\mathrm{A}_{2}$ in Table 2) was larger after sandblasting and anodizing; statistically significant differences were found between these groups and the others (Elias et al., 2008).

\begin{tabular}{|c|c|c|c|c|c|c|c|}
\hline Group & $\begin{array}{c}\mathrm{R}_{\mathrm{a}} \\
(\mu \mathrm{m})\end{array}$ & $\begin{array}{c}\mathrm{R}_{\mathrm{q}} \\
(\mu \mathrm{m})\end{array}$ & $\begin{array}{c}\mathrm{R}_{\mathrm{z}} \\
(\mu \mathrm{m})\end{array}$ & $\begin{array}{l}R_{\max } \\
(\mu \mathrm{m})\end{array}$ & $\begin{array}{l}\mathrm{R}_{\mathrm{pkx}} \\
(\mu \mathrm{m})\end{array}$ & $\begin{array}{c}\mathrm{A}_{1} \\
\left(\mu \mathrm{m}^{2}\right)\end{array}$ & $\begin{array}{c}\mathrm{A}_{2} \\
\left(\mu \mathrm{m}^{2}\right)\end{array}$ \\
\hline Machi & $0.65+0.11$ & $0.81+0.17$ & $6.09+0.37$ & $7.76 \pm 1.37$ & $21.6+0.41$ & $24.71+5.42$ & $70.66+16.20$ \\
\hline Acid & $0.51 \pm 0.10$ & $0.71 \pm 0.07$ & $5.09+0.46$ & $6.78 \pm$ & $1.77 \pm 0.37$ & $34.76 \pm 7.35$ & 103.86 \\
\hline Blasted & $0.75+0.05$ & $0.98+0.04$ & $5.55+0,21$ & $12.44+9.7$ & $6.75+0.76$ & $99.75+6.76$ & $190.13+4.90$ \\
\hline nodized & $0.87 \pm 0.14$ & $1.12 \pm 0.18$ & $5.14+0.69$ & $19.84+2.13$ & $16.71+2.47$ & $97.67 \pm 11.43$ & $215.37 \pm 1.67$ \\
\hline
\end{tabular}

Table 2. Mean value \pm SD of titanium cylinder surface roughness parameters.

A previous study (Links et al., 1998) pointed out the importance of the surface topography of implants on the regulation of the osteoblast physiology. For instance, on smooth surfaces osteoblasts seem to have decreased adhesion, but proliferate at a high extent. On rougher surfaces they seem to adhere further, proliferate at a low extent and show an increased protein secretion, resembling a more differentiated phenotype. However, if the peaks of the surface topography are too high or the distance between them is too great, the cells may be essentially dealing with smooth surfaces.

Also important is the osteoblast attachment, which is affected by surface treatment. Menezes et al. (Menezes et al., 2003) analyzed osteoblast adhesion onto titanium implant acid etched (HNO3) for 20 seconds (Group 1), 60 seconds (Group 2) and 90 seconds (Group 3). They observed a tendency of increase in cell attachment as the surface becomes rougher. Figure 11 shows the influence of osteoblast attachment onto surface acid etched during different time. Data concerning cell attachment reveal a tendency of smooth surfaces to be a poorer substrate for osteoblast attachment when compared to rougher ones. (Eriksson et al., 2001) demonstrated that leukocyte adhesion on rough titanium surfaces is higher as well as its expression of adhesion receptors when compared to smooth counterparts. This could also occur with osteoblasts onto titanium surfaces.

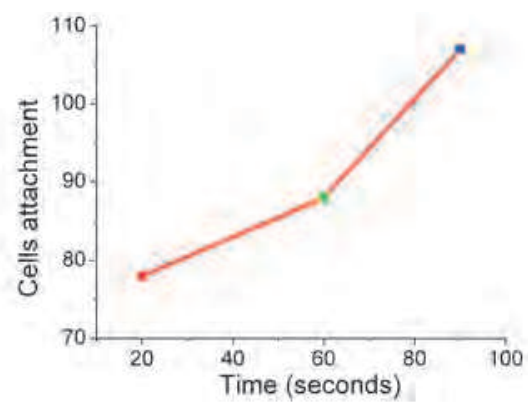

Fig. 11. Osteoblast cell attachment on titanium surfaces acid etched after 20, 40 and 60 seconds. (Adapted from Menezes et al., 2003) 
The fact that osteoblasts on smoother surfaces exhibited a lengthened shape may be reflecting the grooves on the surface formed by the machining tolls (figure 12) Cells tend to grow along the grooves where those are seen. In consequence, if the grooves of the surface are arranged parallel to each other, cells become arranged in the same way. Osteoblasts also tend to spread over large areas in smooth surfaces. Thus, a rectangular shape and an arrangement in a continuous monolayer are expected to occur. Menezes et al. (Menezes, 2003) conclude in their work that smooth implant surfaces are poorer substrates for osteoblast attachment. Also, differentiation of the cells surrounding the implant should be the primary concern as long as a calcified bone around the implant is wanted.

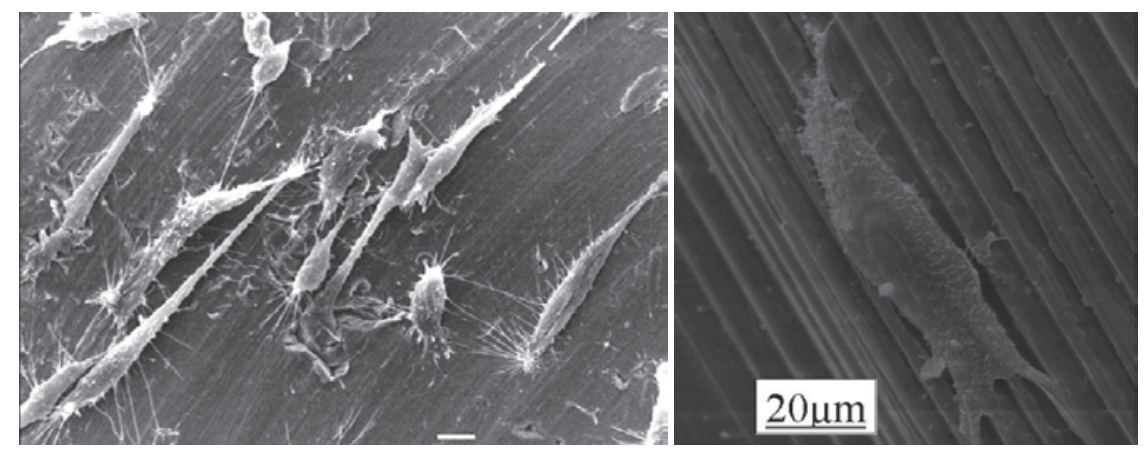

Fig. 12. Osteoblast cells growing along the grooves. (Menezes et al. 2003)

\section{Influence of the implant surface on primary stability}

Javed and Romanos (Javed \& Romanos, 2010) evaluated the role of primary stability for successful of immediate loading (IL) of dental implants. This analysis is important because a fundamental prerequisite for implant success is substantial primary stability at the time of insertion and following loading of the implant. It may be considered as the unifying principle behind the need for adequate bone volume and density, longer or wider implants, and the 3-6-month delay recommended before implants are placed in function. A poor primary stability is one of the major causes of implant failure.

Although establishment of a good primary stability has been the primary focus during implant placement, there are numerous other factors that may contribute to the initial retention of the implant. Therefore, it is critical to maintain the integrity of the peri-implant tissues since bone resorption takes place with or without implant placement in the fresh extraction site. Specifically, for immediately loaded implants, the role of the primary implant stability with the surrounding, mature bone seems to be crucial for long term success.

Studies have shown that surface topography and roughness positively influence the healing process by promoting favorable cellular responses and cell surface interactions. Implant surface characteristics have also been shown to influence primary stability (Santos et al., 2009). Rough surfaces are considered to enhance primary stability as they present a larger surface area and allow a firmer mechanical link to the surrounding tissues (Romanos et al., 2002). Figure 13 shows the influence of surface finishing on dental implant primary stability. 


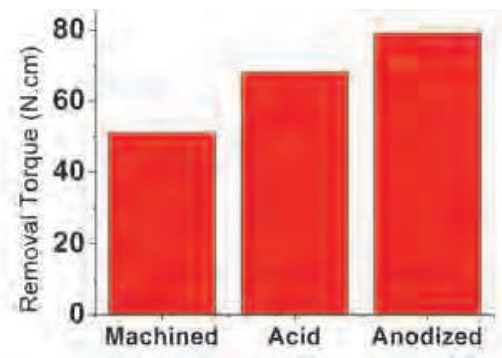

Fig. 13. Effect of the implant surface treatment on the insertion torque (N.cm). (adapted from Santos et al., 2009)

The primary stability of an implant fixture at the time of placement is often estimated by judging the presence of any mobility. In clinical work, primary stability can be evaluated either by the mobility from percussing an implant with a blunt instrument such as a mirror handle. The follow up of the implants can be estimated by devices such as Periotest, Periometer, resonance frequency analysis (RFA) and placement torque. Some factors affect the implant's primary stability, including the bone density, the implant design, the surgical technique, the insertion torque, and the instrumentation protocol. Among these parameters, the insertion torque has not yet been sufficiently analyzed. The insertion torque is a function of the implant surface treatment, design, and screw-thread geometry.

Santos et al. (Santos et al., 2009) analyzed the influence of dental implant surface on primary stability. Their results showed that the maximum torque to insert the implant depends on the friction coefficient between the implant surface and the placement wall, implant design, implant thread geometry and surface treatment.

For the same finishing surface, the differences in insertion torques reflect different implant geometries. The torque to install a conical implant is larger than the torque to install a cylindrical implant (figure 14). This difference can be attributed to the different thread geometry. Figure 8 and 15 show the cylindrical and the conical implants threads geometries. The screw threads are different in cylindrical and conical implants. The thread geometry of the conical implant increases the implant surface area in contact with the host tissue. The reduction in pitch of the conical implant thread increases its contact area as compared to the cylindrical implant. The conical implant has a larger area than the cylindrical implant (table 1). As surface area increases, the friction surface between the implant and the site wall increases, demanding a larger insertion torque.

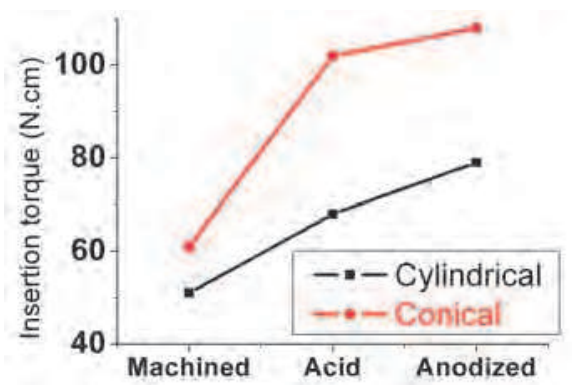

Fig. 14. Effect of the dental implant design and surface treatment on the insertion torque (N.cm). (adapted from Santos et al., 2009). 
The implants submitted to a surface treatment presented a higher roughness and higher friction coefficient than the machined one. The implant that required the smaller insertion torque was the machined one, which possesses a smooth surface compared to the acidetched or anodized samples. The insertion torque for the acid-etched implant was significantly different from the anodized implant.
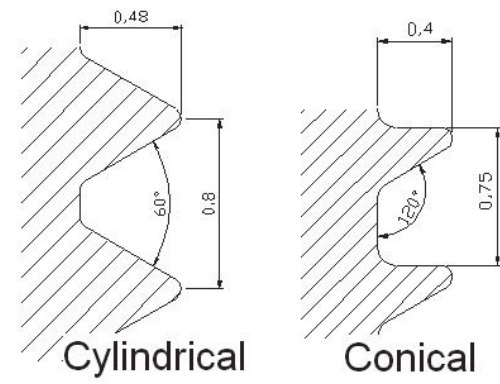

Fig. 15. Thread geometries of implants with cylindrical and conical design.

Javed et al. (Javed et al., 2011) reviewed the influence of surface morphology on the primary stability of dental implants. They conclude that rough-surfaced implants have significantly higher success rates compared with dental implants with smooth surfaces. Although the results in the literature show a direct relationship between surface roughness and overall implant stability, the influence of surface roughness on primary stability remained undetermined. Therefore, it is important to differentiate the initial implant stability gained from surface topographical features from that gained by the BIC.

\section{Wettability}

Dental implant surface wettability influences the degree of contact with the physiological environment. Highly hydrophilic surfaces seem more desirable than hydrophobic ones in view of their interactions with biological fluids, cells and tissues. Complete moistening and distribution of a liquid on a surface indicates high surface energy, biocompatibility and hydrophilicity of a material. Measurement of the contact angle of a liquid is one way to quantify the surface free energy of solids or the ability of the liquid to wet the solid. When the contact angle is greater than 90 degrees the surface is hydrophobic, as opposed to less than 90 degrees, when the surface is hydrophilic.

When a drop is placed in contact with the surface of a solid, there is interaction between the atoms of the liquid, the solid and the surrounding air. This interaction is observed in form of an attractive force between the atoms of the three materials. The greater the interaction between the surface and the liquid, the greater is the flattening of the drop (figure 3).

Baier and Meyer (Baier \& Meier, 1988) related the critical surface tension between implants and biocompatibility. According to these authors, materials with high surface free energy adsorb more easily and have a higher number of favorable sites to allow connections to the cells. The general rule is that materials with a surface tension between 20 and 30 dynes $/ \mathrm{cm}^{2}$ exhibit low adhesion and materials with surface tension above this range have better results for osseointegration. 
Baier (Baier \& Meier, 1988) observed the effect of surface energy of titanium in bioactivity and found that the thickness of the protein that forms on the surface of the implants after 10 days of deployment depends on the surface energy. Histological observations made on implants with high surface energy indicated that they have layers of proteins with greater thickness than those with low energy. The cellular activity varies with the surface energy of the sample. When implants with low surface energy were mechanically separated from the capsule tissue and analyzed under a microscope, it was found that soft tissues occurred in most of the surface. It was observed that the host tissue in contact with implant with low surface energy has cells with globular appearance, almost spherical, that can easily be separated. The globular appearance of these cells identified them as fibroblasts and is associated with poor cell growth, but is not related to the normal activity of fibroblasts in the healing process.

Elias et al. (Elias et al., 2008) analyzed the influence of the dental implant surface treatment on contact angle and on removal torque (Table 3). The results showed that the surface treatment changes the surface wettability. The implants with treated surfaces showed greater roughness, higher friction coefficient, lower contact angle and demanded a larger insertion torque than machined implants. The contact angle of $\mathrm{NaCl}$ (highest hydrophilic liquid tested) with the anodized surface had the smallest value. No statistically significant difference $(P<0.05)$ in the contact angle between blood and any titanium surface was observed, except between blood and the anodized surface.

\begin{tabular}{|c|c|c|c|c|c|}
\hline & \multicolumn{4}{|c|}{ Mean value + SD contact angle (degree) } & \multirow{2}{*}{$\begin{array}{c}\text { Removal } \\
\text { Torque (N.cm) }\end{array}$} \\
\hline Implant Treatment & Water & DMSO & $\mathrm{NaCl}$ & Blood & \\
\hline Machined & $85.20 \pm 3.55$ & $72.4 \pm 2.3$ & $51.6 \pm 1.8$ & $66.4 \pm 0.5$ & $57.0 \pm 18.6$ \\
\hline Acid etched & $96.24 \pm 9.20$ & $68.7 \pm 2.5$ & $44.4+1.6$ & $61.6 \pm 0.7$ & $75.45 \pm 10.5$ \\
\hline Sandblasted & $79.86 \pm 4.85$ & $52.5 \pm 2.6$ & $43.0 \pm 0.9$ & $61.8 \pm 0.1$ & $72.15+14.9$ \\
\hline Anodized & $47.25 \pm 2.94$ & $38.3 \pm 2.1$ & $25.3 \pm 1.3$ & $55.5 \pm 0.3$ & $83.15 \pm 12.7$ \\
\hline
\end{tabular}

Table 3. Mean value \pm SD contact angle of treated titanium surfaces and dental implant removal torque from rabbit.

\section{Influence of bone}

Theoretically, for implants with the same dimensions, the choice of surface finishing is based on the type of bone that will receive the implant. Lekholm and Zarb (Lekholm \& Zarb, 1985) classified the types of bones based on the quality of cortical bone and trabecular bone density. According to them, the bones can be classified as type D1, D2, D3 and D4.

The D1 bone has dense cortical and trabecular bone. Clinically, the D1 bone has little bleeding during surgery, indicating a slight vascularization. Because it is a harder bone, one should take extra care during the preparation of the implant insertion site to prevent overheating. Localized heating prevents the initial necrosis, which can be prolonged by ischemia caused by compression of the implant on the walls of the bone, keeping the contact area of bone in a state of compression. Implants with a length of $10 \mathrm{~mm}$ can be used.

The D2 has satisfactory cortical bone and a less dense and vascularized trabecular bone. In D2 bone there is lots blood in contact with the implant surface and initial stability is good. The implant should be at least $12 \mathrm{~mm}$ length and is required that at least $50 \%$ of the surface keeps the initial contact with the bone. 
The cortical and trabecular in D3 bone is less dense than D2 and lower mechanical strength. Clinically, it is a brittle bone, with cortical and trabecular fragile little dense, which can often lead to poor initial anchor the implant.

The D4 bone has cortical papyracea (slender), slightly mineralized trabecula and has low mechanical strength. This type is very fragile, leading to a delicate surgical procedure to achieve initial implant anchorage.

Normally, the bone is of type D1 and D2 in the region between the mental foramen in the mandible and anterior maxilla. The bone type D3 can be found in the region of upper premolars and lower type D4 and will always be found in the molar region of mandible and maxilla.

For bone D1 and D2 can indicate machined dental implants without surface treatment. For the bone type D3 and D4 must be employed treated implant surface, which has higher contact area than machined and can improve the mechanisms involved in osseointegration. For the D3 and D4 bone type should always choose implants with surface treatment Misch (Misch, 2008) suggested for the D4 bone the use of implants larger than $12 \mathrm{~mm}$ and the largest diameter possible. The cavity preparation must be done very carefully, since due to low mechanical strength of bone, small lateral movements can easily move the slope of the planned implant.

\section{Influence of surface morphology on implant osseointegration}

Although titanium is used extensively as a biomaterial, there are still doubts about the procedure to obtain the best biological response. When analyzing the importance of the surface of the implant osseointegration to occur, one should separate the discussion of the influence of implant shape (design) and surface morphology. In shape analysis consider the dimensions of the implant (length, diameter, thickness), shape (barrel shape, cylindrical, conical and hybrid), type of threads (triangular, square, trapezoidal, rounded, microthread), height of fillets of threads, the thread angle, thread pitch and implant-prosthesis connection type (extern hexagon, internal connection in the form of a hexagon, cone Morse, star grip). These parameters influence the primary stability, the distribution of forces and mechanical properties of the implant. As for surface morphology should be analyzed macro and nanomicroestructure as well as the homogeneity of the surface, the chemical and physical properties.

Several researchers (Wennerberg et al., 1998; Hayakawas et al., 2000; Kokubo et al., 1999) examined the influence of surface properties of titanium implants on bone apposition into surface and the results showed that the biological response depends on the morphology, surface composition and titanium oxides on the implant surface in contact with the physiological environment. These results are important because the dentistry selects the roughness of the implant according to the surgical protocol, site of insertion, quality and quantity of available bone.

The surface properties of implants such as morphology, roughness, thickness of the oxide layer, impurity level and types of oxides depend on the surface treatment process. The difficulty in analyzing the influence of these parameters is the current inability to change only one parameter at a time keeping the others unchanged. For example, it is not feasible to modify only the titanium oxide crystalline structure or chemical composition, without change the oxide thickness.

During insertion of the implants immediately after the surface comes in contact with blood, a protein cover the implant surface. Titanium in contact with the physiological environment 
absorbs molecules from the plasma, as so absorb factor I, factor III, Ig G and C1q. A few seconds after inserting the implant can find polymorphonuclear granulocytes and platelets adhered on its surface. Then there is the adhesion of mature granular leukocytes, neutrophils, basophils and acidophilus. The granulocytes polymorphonuclear leukocytes are the first recruited by the titanium surface exposed to contact with blood. Depending on the surface preparation is no difference in the absorption and reaction of cells exposed to titanium by contact with human blood (Werner et al., 2009; Puleo \&Bizios, 1992; Kasiwagi et al., 2009; Novak et al., 2009; Eriksson et al., 2001). The adhesion of monocytes (mononuclear leukocytes of intense phagocytic activity, representing 3-7\% of circulating blood leukocytes) is sensitive to variations in the thickness of the titanium oxide layer (Eriksson et al., 2001). Polymorphonuclear granulocytes are more dependent on surface roughness of the implant. Macrophages prefer areas with lower roughness.

A few months after insertion, the implants with treated surface have a higher amount of bone overlying the surface than machined implants with lower roughness. Possibly, the success depends on the speed of osteogenesis around the implant, ie, early osteoblast adhesion on implant surface. Despite this finding, it is unclear how the implant surface promotes or inhibits osteogenesis. The behavior of cells is dependent on the interaction of action and triggering activity of the cells and molecules (Henessy et al., 2009).

Cells have mechano-receptor properties that can identify whether or not the surface has features appropriate to begin the process of differentiation and bone matrix. The proteins attached on the surface of the implants induce adsorption and pre-osteoblastic cells. Research results show that the surface treatments affect the interfacial forces, wettability, roughness, energy and adsorption capacity of the molecules that recognize osteoblasts (Eriksson et al., 2001). Biomaterials in contact with the biological environment suffer dynamic changes in their surface properties, involving a cascade of reactions at the interface between the environment and biomaterial, forming a "conditioning film" that modulates the responses cellular (Puleo \& Bizios, 1992). The wettability and surface energy influence on the adsorption of proteins and increase focal adhesions of osteoblasts on the surface of implant (Kashiwagi et al., 2009).

\section{Surface treatment of implants}

Numerous surface modification approaches have been developed for all classes of dental implants to modulate biological responses and improve the osseointegration and primary stability. Study of the surface treatment of dental implants is multidisciplinary, involving researchers from Materials Science, Mechanical Engineering, Mathematics, Computer Science, Dentistry, Surgery, Biophysics and Veterinary Medicine. The involvement of professionals from various fields and diverse knowledge facilitates the work, the analysis of results and development of new shapes and surfaces for the implants. Research results show that despite of the high success (95 to $98 \%$ ) of titanium dental implants, it is necessary to analyze the surface characteristics of the implant with respect to surface finishing, physical properties, chemical composition, residual stress, morphology, microstructure and type of oxide (Henessy et al., 2009). A finishing deficiency of the implant can jeopardize the success of surgery, especially when there are contaminants from the manufacturing process, presence of burrs and stress concentration that compromises the mechanical performance of the implant during loading. 
The success of dental implants will not occur when the implant surface morphology does not present features that allow adhesion and cell growth. The problem is increased by the presence of contaminants, mainly alumina particles used in the blast, which are toxic and lead to apoptosis. The deleterious effect of the existence of machining chips or holes in the surface of the implants refers to the possibility of these defects releases during implant insertion into the cavity and compromise the osseointegration. The process of machining and processing further determine the surface properties of implants, especially the electronic structure, crystalline oxide, chemical composition, mechanical and chemical properties.

The primary stability depends on the shape and surface morphology of implant. The secondary stability depends mainly on the implant surface. The differences among surfaces of available dental implants are the roughness, chemical composition, surface energy, chemical potential, the segregation of hydrides and nitrides, work hardening, the presence of metallic and nonmetallic, existence of impurities resulting from the manufacture or handling, type titanium oxide, crystal structure and oxide thickness of the oxide layer. This is important since the proteins interact with the oxides of the implant surface and the interaction depends on these parameters.

Surface roughness of dental implants can be analyzed in three orders of magnitude: macroscopic, microscopic and nanoroughness. Each size of the roughness provides contacts with different cells and biological molecules and is responsible for the intensity and types of biological bonding. A priori, it is expected that the increased surface area of the implant, increase the number of sites to bind to cells, facilitates tissue growth and increase the mechanical stability. However, this is not a general rule. Fibroblasts avoid rough surfaces and accumulate in the smooth surface. In contrast, macrophages exhibit rugophily behavior, or prefer to attach to rough surfaces. The epithelial cells are more attracted to rough surfaces than for smooth. Osteoblast cells adhere more easily on rough surfaces like those found on commercial implants with treated surfaces than in machined (Jayaraman et al., 2004; Le Duc \& Wang, 2006; Thull, 2002; Lim et al., 2004).

The chemical composition of the surface determines the stability and reactivity of the implant, which shall consist solely of titanium oxide. Although there are no conclusive studies of the influence of impurities on the surface of the implants, the surface should contain the lowest possible levels of contamination. The surface energy and the existence of residual stresses after sandblasting modify the reactivity of the surface. Implant with coating has a complete different behavior. The coating modifies the behavior of cells and cascade reactions.

The surface morphology of dental implants is modified by chemical, mechanical and electrochemical treatments. By treating the surface of implants is possible to reduce the healing and loading time after surgery, accelerate growth and bone maturation, to increase the primary stability and to ensure the successful application in bone with less quality and quantity. There are many variables, combinations of parameters related to the implant surface treatment and factors that influence osseointegration (material, implant shape, implant surface, bone quality and quantity, surgical technique and loading condition).

The companies adopt a variety of techniques for surface treatment of commercial implants. By treating the surface of implants, it is possible to increase the stability, the wettability, the contact between implant and bone, the strength of the bone-implant interface and the success of treatment in patients seen as critical. Furthermore, it is possible to improve the retention of tissue, stimulate the healing process and reduce the loading time.

The choice of the methodology to be used in surface treatment is initiated by selecting the desired roughness, since the procedures for macroroughness, microroughness and 
nanoroughness are different. The current trend is to obtain hybrid surfaces, i.e., a morphology with micro- and nanoroughness. In some cases, the chemical composition of the implant surface is changed with addition of calcium, phosphorus and fluoride (Ellingsen et al. 2004). The precise role of surface chemistry and topography on the early events in dental implant osseointegration remain poorly understood.

For study purposes, the surface modification of dental implants shown in figure 7 and 9 can be divided in the followings classes:

a. machined surface (untreated surface);

b. plasma spray;

c. laser treatment;

d. acid etching;

e. sandblasting and sandblasting followed by acid etching;

f. anodizing;

g. deposition of nanoparticles by physical or chemical methods.

\subsection{Implants with untreated surface (as machined)}

Implants with untreated surface (machined) were the first to be used, but are seldom employed nowadays After manufacturing, these implants are subjected to cleaning, decontamination, passivation, and sterilization. The implants without surface treatment are inappropriately called "smooth". The term "smooth" is inadequate, since scanning electron microscopy shows that the surface of these implants has tool marks from the machining process (figure 9).

The disadvantage regarding to the morphology of untreated implants is the fact that osteoblastic cells are rugophilic - that is, they are prone to grow along the grooves existing on the surface, as shown in figure 12. This characteristic requires a longer healing time between surgery and implant loading. The use of these implants follows a protocol suggested by Brånemark: 3-6-month healing or waiting time prior to loading. Owing to morphological characteristics and lower resistance to removal torque (Table 1), machined dental implants are becoming commercially unavailable.

\subsection{Surface treatment with plasma spray and laser}

Two alternative surface treatments are laser ablation and plasma spraying the surface with a ceramic. After both treatments the implant surface has a large roughness (figure 7), which can be characterized as an area under macroroughnesss. The macroroughnesss influence the primary stability and mechanical fixation of bone formation but does not alter the behavior of cells during the period of osseointegration.

Gaggl et al. (Gaggl et al., 2000) cited that (i) surfaces of laser-treated Ti implants showed a high purity with appropriate roughness for good osseointegration, and (ii) the laser-treated Ti had regular patterns of micropores with interval of 10-12 $\mu \mathrm{m}$, diameter of $25 \mu \mathrm{m}$, and depth of $20 \mu \mathrm{m}$.

Cho and Jung (Cho \& Jung, 2003) evaluated the significance of different surface textures by comparison of the removal forces for laser-treated and machined titanium screw 8 weeks after the installation in rabbit tibia. They observed that laser treatment created a deep and regular honey-comb pattern with small pore, while machined treatment created the typical microscopically grooved and relatively smooth surface characteristic. In the laser surface, the distance between the pore was 10-12 $\mu \mathrm{m}$. Eight weeks after implant placement, the 
average removal torque was $23.58 \pm 3.71 \mathrm{Ncm}$ for the machined implants, $62.57 \pm 10.44 \mathrm{Ncm}$ for the laser-treated implants.

The micropores in laser treated implants, evaluated by Gaggl et al. (Gaggl et al., 2000) and by Cho and Jung (Cho \& Jung, 2003), do not improve osseointegration. Figure 16 shows the morphology of an implant surface treated with a laser. The surface exhibits macroroughness at low magnification, whereas melting structures can be observed at high magnification. At higher magnification, a laser-treated surface is smoother than acid etching. The best implant surface has microroughness and nanoroughness.
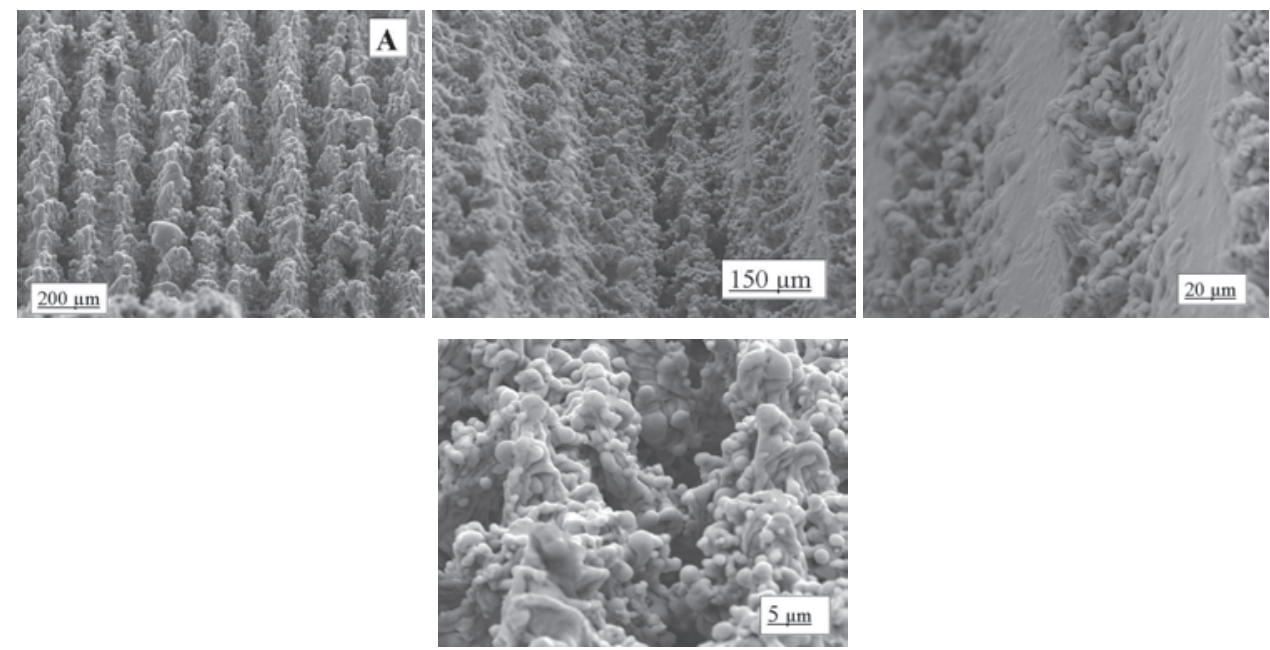

Fig. 16. Surface morphology of titanium after laser treatment. The surface has macroroughness and at high magnification shows melting structure.

Cordioli et al. (Cordioli et al., 2000) reported that average removal torque value was 25.28 $\mathrm{N} \cdot \mathrm{cm}$ for the machined implants, $26.85 \mathrm{~N} \cdot \mathrm{cm}$ for the grit-blasted implants, $29.57 \mathrm{~N} \cdot \mathrm{cm}$ for the plasma-sprayed implants, and $40.85 \mathrm{~N} \cdot \mathrm{cm}$ for the acid-etched implants under similar conditions. Their results showed that removal torque value of plasma-sprayed implants has approximately the same value of machined or grit-blasted implants.

Plasma spraying and laser treatments are no longer being used, because of the resulting macrorugosities. It is expected that surface characteristics exhibit biological influence during implant installation and interaction with cells by modifying the mechanisms involved in cell adsorption and differentiation.

The osseointegration of dental implants with plasma-sprayed HA is faster than for uncoated implants. However, studies have shown that these coatings may be partially dissolved/resorbed after long periods in use (Sun et al., 2001). [. In addition, the HA coating is chemically unstable and bonds weakly to the implant surface.

Considering the potential of the association between laser ablation and smaller scale HA coatings to create a stable and bioactive surface on titanium dental implants, Faeda et al. (Faeda et al., 2009) analyzed the effects of a surface treatment by laser-ablation (neodymium-doped yttrium aluminum garnet [Nd:YAG]) and, later, thin deposition of HA particles by a chemical process. They compared the removal torque of implants treated with 
laser followed by acid etching, implants with only laser-ablation and implants with machined surface (MS). After 4, 8 and 12 weeks of healing, the removal torque was measured. Average removal torque in each period was 23.3, 24.0 and $33.9 \mathrm{~N} \cdot \mathrm{cm}$ for MS, 33.0, 39.9 and $54.6 \mathrm{~N} \cdot \mathrm{cm}$ for laser modified surface (LMS), and 55.4, 63.7 and $64.0 \mathrm{~N} \cdot \mathrm{cm}$ for HA (Figure 21). The difference was statistically significant $(p<0.05)$ between the LMS-MS and HA-MS surfaces for all evaluation periods, and between LMS-HA for 4 and 8 weeks of healing. The surface characterization showed a deep, rough and regular topography provided by the laser conditioning that was followed by the HA coating. They conclude that the implants with laser surface modification associated with HA biomimetic coating can shorten the implant healing period by the increase of bone implant interaction during the first 2 months after implant placement.

Although the use of hydroxyapatite-coated endosseous implants in the treatment of dental patients has been established, their clinical predictability remains controversial. A number of clinical and basic studies evaluating the effect of HA coating have been reported. Concerns regarding microbiological susceptibility, resorption, fatigue, and fracture in longterm application have been pointed out. Clinical studies suggest that HA-coated implants have short-term survival rates (ranging from 6 months to 6 years) that are comparable to short-term survival rates of titanium implants (Biesbrock \& Edgerton, 1995). In conclusion, the clinician needs to take into consideration the enhanced bacterial susceptibility of HA coatings compared with titanium implants. In addition, the clinician needs to consider the possible failure of HA coatings as a result of coating-substrate interfacial fracture (Ong \& Chan, 2000). Dental implants with titanium or hydroxyapatite coating produced by plasma spray are in disuse.

Among commercially available dental implants coated with hydroxyapatite using the plasma spraying technique one can cite the Bonelike ${ }^{\circledR}$ (Biomet 3i, USA) and Calcitek (Sulzer Calcitek Inc., USA)

\subsection{Surface treatment with acid}

The acid etched dental implant surface presents a superficial morphology that varies with the treatment conditions (acid, chemical composition percentage, etching time and temperature treatment). Through acid etching, it is possible to control the roughness, number, size and porous distribution on micrometer and nanometer scales.

Every manufacturer has its own acid etching method regarding concentration, time and temperature for treating implant surfaces. In general, acid treatment is performed by immersing the implants into solutions of $\mathrm{HCl}+\mathrm{H} 2 \mathrm{SO} 4, \mathrm{HF}+\mathrm{HNO} 3$ and $\mathrm{HNO} 3$. After acid attack, the implant is again immersed into an aqueous solution of HNO3 for passivation of titanium oxide and formation of a stable oxide layer (Elias \& Meirelles, 2010). An example of the morphology of an acid-etched surface of a commercially available implant is shown in figure 17.

Acid treatments provide homogeneous roughness, increased active surface area and improve cells adhesion. The morphology of the implant surface shown in figure 16 is isotropic and exhibits micro-cavities with defined edges. This type of surface not only facilitates retention of osteogenic cells, but also allows them to migrate towards the implant surface. Implants having surface morphology similar to that shown in figure 16 induce fibrin retention, favor adsorption of fibronectin and improve the osseointegration (Brunette, 2001; Braceras et al. 2009). 

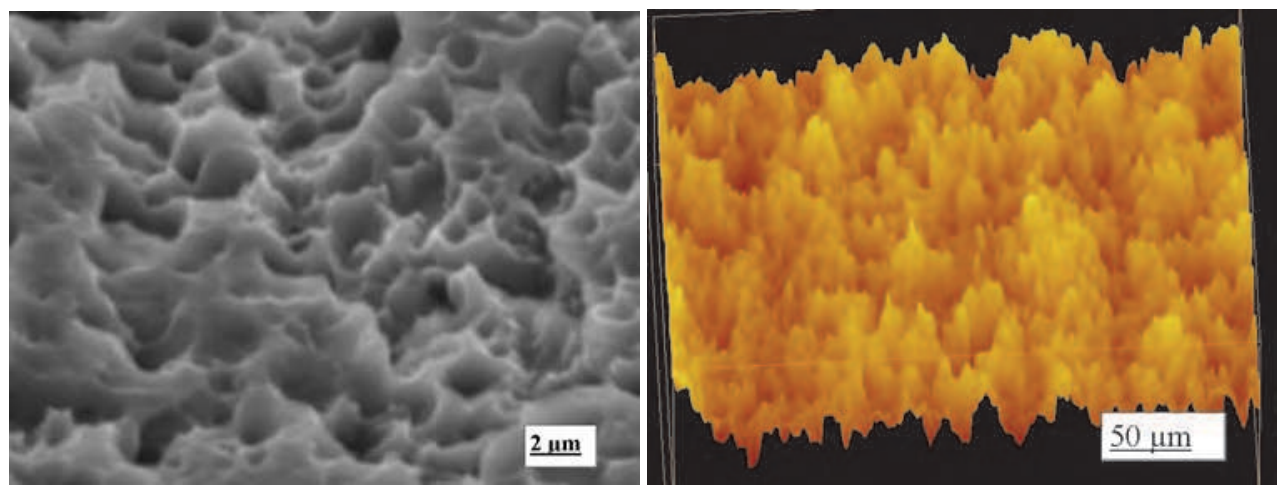

Fig. 17. Surface morphology of dental implant Master Porous ${ }^{\mathrm{TM}}$ acid etched, showing microporous.

As Table 3 and figure 14 show, the removal torque of acid etched implants is higher than that of machined implants, which means that the osseointegration mechanisms are faster in acid treated implants than machined implants

Among the commercially available acid-treated implants, one can cite the Master Porous System ${ }^{\circledR}$ (Conexão Sistema de Próteses, Brazil), Osseotite ${ }^{\mathrm{TM}}$ (Biomet 3i, USA), Friadenty Plus ${ }^{\circledR}$ (Friadent $\mathrm{GmbH}$, Germany), Defcon TSA ${ }^{\circledR}$ (Impladent SL, Spain) and BlackFix® (TitaniumFix, Brazil).

Wennerberg (Wennerberg et al., 2003) analized some samples of the Osseotite ${ }^{\mathrm{TM}}$ implants and measured the roughness surface parameters. They showed that the Tioblast ${ }^{\mathrm{TM}}$ has $\mathrm{S}_{\mathrm{a}}=$ $0.94 \mu \mathrm{m}, \mathrm{S}_{\mathrm{cx}}=11.68$ and $\mathrm{S}_{\mathrm{dr}}$ increased.

\subsection{Sandblasting surface treatment}

When the implant is blasted with silicon oxide (silica), aluminum oxide (alumina), titanium oxide (rutile), hydroxyapatite and calcium phophate, the implant surface suffers plastic microdeformation. The sandblasting process induces the formation of a fine superficial layer with residual stress. Part of the kinetic energy of the particles is stored in the form of crystal defects, such as dislocations, twins and grain boundaries, and these modifications increase the material surface energy. The superficial layer with residual compressive stress increases the material's fatigue resistance (Askeland, 2006). The residual stress values obtained from blasting procedures depend on both hardness and particles size distribution. The influence of residual stress has not been analyzed in the field of dental implants.

The influence of surface roughness on bone formation on titanium-blasted surfaces was evaluated by Wennerbeg et al. (Wennerbeg et al., 1995). The samples were blasted with $\mathrm{Al} 2 \mathrm{O} 3$ particles. After surface preparation, the samples were passivated, washed with distilled water and dried. The results from animal experiments showed higher values for removal torque and bone-to-implant contact for samples blasted with $25 \mu \mathrm{m}$ and $75 \mu \mathrm{m}$ sized particles compared with those machined or blasted with $250-\mu \mathrm{m}$ particles.

The blasting procedure allows control of the size of microcavities. After the grit blasting procedure some particles may be encrusted on the implant surface, which is a contamination (figure 18). The particle must be removed with ultrasonic bath and acid etching. 

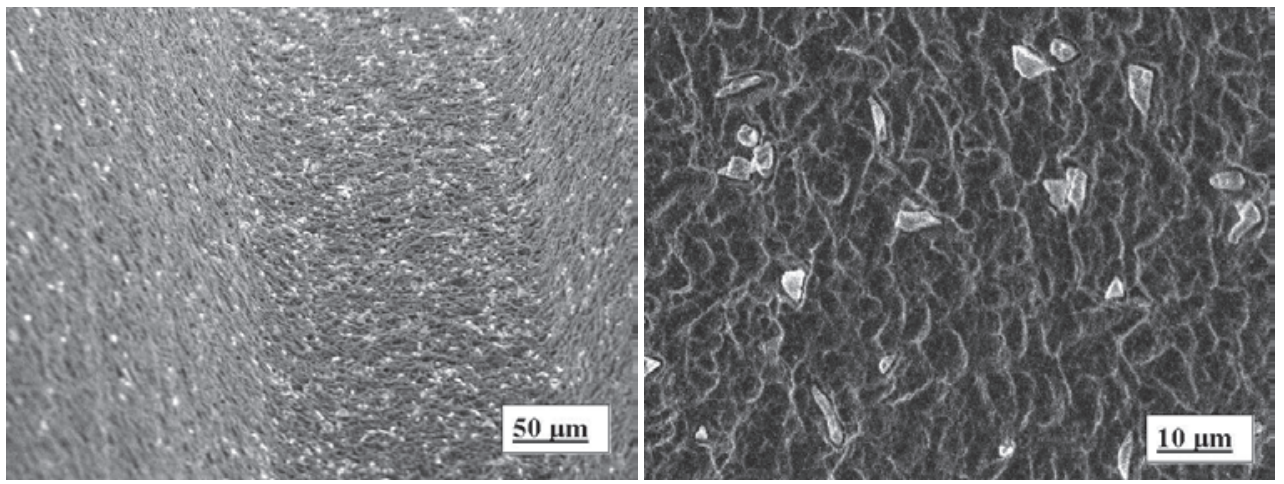

Fig. 18. Particles of alumina (left) and titanium oxide (right) encrusted on the sandblasted implant surface.

Sandblasting with $\mathrm{TiO} 2$ is also adopted in the production of implants Tioblast ${ }^{\mathrm{TM}}$ (Astra Tech Implant System, Sweden) and TitaniumFix BlackFix (TitaniumFix Implant, Brazil). Tioblast ${ }^{\mathrm{TM}}$ is gritblasted with $25-\mu \mathrm{m}$ titanium oxide particles, which create small pits of predetermined size and shape. Another example of sandblasted implant is Bicon (Bicon LLC, Boston, MA) which is alumina-blasted/acid-etched titanium alloy substrate.

Wennerberg (Wennerbeg et al., 2003) evaluated the Tioblast ${ }^{\mathrm{TM}}$ implant. Their results showed this implant has $S_{a}=1.07 \mu \mathrm{m}, S_{c x}=10.11 \mu \mathrm{m}$ and the surface parameter $S_{d r}$ increased $29 \%$.

Another procedure to implant surface treatment is acid etching after blasting. Acid treatment after blasting removes some atomic layers of the titanium surface deformed by the blasting procedure, but part of the residual strain remains at the implant surface.

Available implants SLA ${ }^{\mathrm{TM}}$ (Sand-blasted, Large grit, Acid-etched) from Straumann (Straumann ITI, Germany) are sandblasted and acid etched. Alumina particles in the size range $25-50 \mu \mathrm{m}$ are used to sandblast the SLA ${ }^{\mathrm{TM}}$ implant. Sandblasting is followed by an acid etch in hot $\mathrm{HCl} / \mathrm{H} 2 \mathrm{SO} 4$ acid solution. These processes create micropits superimposed on the rough-blasted surface. Jarmar et al. measured the roughness on SLATM and found it to be $1.98 \pm 0.08 \mu \mathrm{m}$ (Jarmar et al., 2008). Another way Wennerberg et al. (Wennerbeg et al., 2003) verified that SLATM implant has $S a=1.42 \mu \mathrm{m}$, waviness parameter $S_{c x}=16.60 \mu \mathrm{m}$ and the surface parameter $S_{\mathrm{dr}}$ increased $33 \%$.

\subsection{Surface treatment with fluoride}

It is known that fluoride ions have osteopromoting capacity leading to increased calcification of the bone. One of the characteristics of fluoride is its biphasic nature. Fluoride produces beneficial effects when used in low concentrations and toxic effects if used in high concentrations. In therapeutic doses, it is capable of causing mass increase of cortical and trabecular bone. If used in excessive doses, it can lead to bone deficient in collagen crosslinks and with increased solubility. With high doses of fluoride, the tensile mechanical properties of the bone are reduced.

Fluoride increases proliferation and differentiation of osteoblasts (Cooper et al., 2006). Ion modification of the topographically enhanced c.p. titanium surface can affect bone formation by modulation of cellular activities at relatively early stages in wound healing at the implant surface. Fluoride increases the alkaline phosphatase activity and increases collagen synthesis. 
According to Cooper et al. (Cooper et al., 2006) in vitro evaluation of hMSC (human mesenchymal stem cells) differentiation along the osteoblastic lineage demonstrated that fluoride ion modification of the $\mathrm{TiO} 2$ grit-blasted surface led to greater osteoblastic differentiation by adherent hMSCs. This conclusion is most strongly supported by the assessment of BSP expression showing greater expression on all fluoride ion-modified surfaces. The increased BSP expression observed in hMSCs cultured on fluoride ionmodified c.p. titanium was consistent. Whenever the fluoride surface ion content was greater than 5.0 ion $\%$ on the $25 \mu \mathrm{m}$ grit-blasted surface, BSP expression increased (4 fold when compared to densitometric scanning versus Actin) and when fluoride surface ion content was greater than 1.0 ion \%, BSP increased 1.6 fold. BSP expression is required for osteoblastic differentiation and mineralization in culture and is temporally associated with the onset of osteoid mineralization in vitro.

Human osteoblastic cells grown on the fluorapatite-collagen composites exhibited significantly higher proliferation and differentiation (according to alkaline phosphatase activity) than those on the hydroxyapatite-collagen composite and the investigators attributed this effect to fluoride release from the fluorapatite containing composite. In addition to direct effects of fluoride ions with osteoblastic cells or indirect fluoride ion effects on protein adsorption and subsequent cell adhesion, another possible indirect effect of fluoride at the c.p. titanium surface could be calcium phosphate precipitation that could influence local calcium concentrations and cell behavior. Ionic modification could alter the array of adhesive proteins adsorbed to the implant surface that could further affect cell and tissue interactions.

There is a relationship between cellular response and the concentration of F-ions (Cooper et al., 2006). For concentrations from 25 to $200 \mathrm{ngF}-/ \mathrm{mL}$, i.e., up to the threshold of toxicity, there is a linear increase of intracellular calcium. If the concentration is raised from 500 to $1000 \mathrm{ngF}-/ \mathrm{mL}$, the intracellular calcium falls to a level lower than for concentrations in the $100 \mathrm{ngF}-/ \mathrm{mL}$ range. The cellular effects mentioned occur for short times of exposure to fluoride ions.

Berglundh et al. (Berglundh et al., 2007) studied the early stages of osseointegration to implants with a fluoride-modified surface. Six mongrel dogs, about 1-year old, were used. All mandibular premolars and the first mandibular molars were extracted. Three months later, mucoperiosteal flaps were elevated in one side of the mandible and six sites were identified for implant placement. The control implants (MicroThreadt) had a TiOblast ${ }^{\mathrm{TM}}$ surface, while the test implants (OsseoSpeed ${ }^{\mathrm{TM}}$ ) had a fluoride-modified TiOblast ${ }^{\mathrm{TM}}$ surface. $^{-}$ The results showed that the amount of new bone that formed in the voids within the first 2 weeks of healing was larger at fluoride-modified implants (test) than at TiOblast ${ }^{\mathrm{TM}}$ (control) implants. It was further observed that the amount of bone-to-implant contact that had been established after 2 weeks in the macro-threaded portion of the implant was significantly larger at the test implants than at the controls. They suggested that the fluoride-modified implant surface promotes osseointegration in the early phase of healing following implant installation. The OsseoSpeed ${ }^{\mathrm{TM}}$ (Astra Tech AB, Sweden) dental implant surface is fluoride-modified (hydrofluoric acid-treated surface). The implant surface is blasted and later etched with diluted hydrofluoric acid, which slightly reduces the high peaks. The final surface structure has an isotropic roughness - that is, there is no preferred direction of the surface irregularities (Ellingsen et al., 2004). During the blasting procedure, the surface roughness is increased. The OsseoSpeed surface has $\mathrm{Sa}=0.91 \pm 0.14 \mu \mathrm{m}$ and the TiOblast ${ }^{\mathrm{TM}}$ surface has Sa $=1.12 \pm 0.24 \mu \mathrm{m}$. The hydrofluoric acid treatment does not only change the microstructure, 
but also the surface chemistry. According to Ellingsen (Ellingsssen, 1995) the surface fluoride incorporated in the oxide acts as a precipitation site for calcium and phosphorus, and also allows covalent bonding to the phosphate to create fluoridated HA and fluorapatite.

\subsection{Anodizing surface treatment and crystalline oxide structure}

One of the methods used to treat the surface of implants is increasing the thickness and change the crystalline structure of the titanium oxide layer on the surface by anodizing.

Anodizing is an electrochemical process where the implant is immersed in an electrolyte while a current is applied, which will make the implant the anode in an electric cell. Commercial dental implants, such as TiUnite ${ }^{\mathrm{TM}}$ (NobelBiocare, Switzland) and Vulcano Actives $^{\mathrm{TM}}$ (Conexão Sistemas de Prótese, Brazil), are anozided. The electrolyte and the current used in the implants treatment process create a porous surface structure (figure 19).
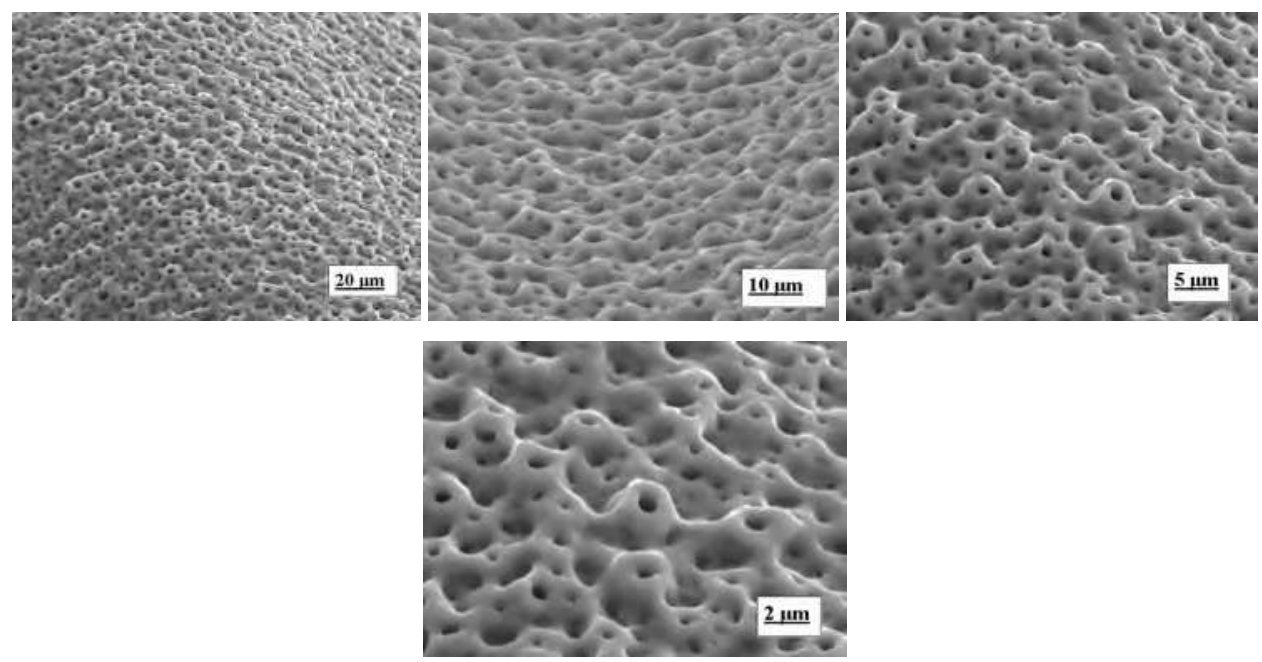

Fig. 19. Anodized dental implant surface, showing volcano shaped saliencies

As Oshida et al. (Oshida et al., 2010) oxides formed on Ti materials are varied with a general form; TiOX $(1<x<2)$. Depending on $x$ values, there are five different crystalline oxides; i.e., (1) cubic TiO (ao = 4.24 $\AA$ ), (2) hexagonal Ti2O3 (ao = $5.37 \AA$, a $\left.=56^{\circ} 48^{\prime}\right)$, (3) tetragonal TiO2

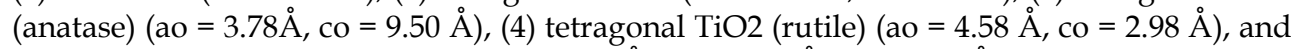
(5) orthorhombic TiO2 (brookite) (ao $=9.17 \AA$, bo $=5.43 \AA$, co $=5.13 \AA$ ). Besides these, there are (6) non-stoichiometric oxide (when $x$ is not integral), and (7) amorphous oxides. It is widely believed that, among these oxides, only rutile and anatase type oxides are stable at normal conditions. Of interest, choice for rutile formation or anatase formation depends on the acidity of used electrolyte. The rutile and anatase type oxides exibit different physical properties - interms of surface tension (Lim et al., 2001) prepared various surface conditions on pure titanium and measured surface contact angles, surface electrochemical potential and roughness. It was found that the surface covered with only rutile type $\mathrm{TiO} 2$ was hydrophobic, whereas that covered with a mixture of rutile and anatase type of oxides showed hydrophilicity. 
Rutile and anatase titanium oxide are the most important oxide structures for osseointegration of implants. In addition to the increase in oxide layer thickness, the titanium oxide film obtained from electrochemical anodizing incorporates calcium and phosphorus as a heritage from the electrolyte. The surface has more than $7 \%$ phosphorus in the oxide layer, the highest percentage of amorphous hydroxides compared with other implants assessed by x-ray photoelectron spectroscopy (XPS). As a result, the titanium oxide existing on the implant surface shows changes in its morphology and crystal structure (Busquim et al., 2009).

Busquim et al. (Busquim et al., 2009) analyzed with x-ray diffraction, Raman and XPS the surface of anodized implant. They found that a predominance of anatase forms on anodized surfaces compared with MS, where the rutile crystal is predominant figure 20).

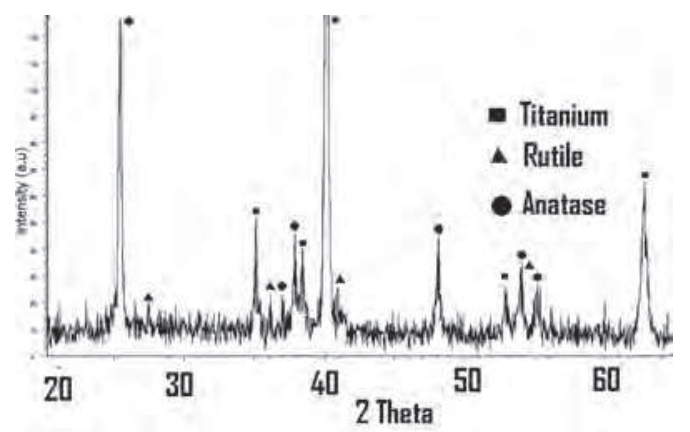

Fig. 20. X-ray diffraction pattern of the anodized titanium surface showing the presence of titanium oxides with crystalline structure in the form of rutile and anatase (dental implant Vulcano Actives ${ }^{\mathrm{TM}}$ ).

The anodized surface implant has a higher polarity compared with that of acid-treated samples, which causes adsorption of water and molecules. Adsorption of these molecules creates an electric field along the oxide thickness. This electric field induces titanium oxidation and, at the same time, the oxide layer thickness increases, thus decreasing both potential difference and the driving force for dissolution (Sul et al., 2006). In this way, taking into account that surface structure as well as morphology are correlated with wettability, changes in their properties affect adsorption of proteins needed for cell adhesion on the implant surface. Consequently, the performance of a given treated surface depends on the biological response of the implants used.

Depending on the anodizing parameters (potential, electrolyte chemical concentration, temperature), the solid oxide layer can be either compact or nanotubular (nanoporous). Figure 18 shows that the oxidized dental implant surface morphology has volcano shaped saliencies. The TiO2 film obtained by electrochemical anodizing incorporates $\mathrm{P}$ and $\mathrm{Ca}$ ions from the electrolyte, which alters the final properties of titanium oxide (Elias \& Meirelles, 2010). Experiments in cell cultures have shown that incorporated calcium ions on the implant surface increase the adhesion of human bone cells to the implant, when compared to unmodified titanium implants and implants with incorporated phosphate ions (Fröjd et al., 2008; Feng et al., 2004; Nayab et al., 2005). Also, the release of alkaline phosphatase from osteoblasts during bone formation has been found to be increased (Feng et al., 2004). The expected effect of the added calcium ions is a more rapid initiation of bone mineralization, 
because of the attraction of bone matrix proteins. The calcium ions may also function as binding sites for initial mineral crystal growth when they bond with phosphate ions in the extracellular body fluid (Ohtsu et al., 2007).

The characterization of the anodized implant surface by X-ray diffraction, Raman and XPS show that the surface of anodized implants shows a predominance of anatase. On machined implant surface the main oxide is rutile (Figure 11) with hydrophobicity. The sandblasted and acid etched implants surfaces OsseoSpeed ${ }^{\mathrm{TM}}$, Osseotite ${ }^{\mathrm{TM}}$, and SLA ${ }^{\mathrm{TM}}$ have rutile too, but their surface morphologies are different of machined implant. The anodized implant Vulcano Actives ${ }^{\mathrm{TM}}$ (Conexão Sistemas e Prótese, Brazil) and TiUnite ${ }^{\mathrm{TM}}$ (Nobel Biocare, Sweden) have rutile and anatase on the surface (figure 19).

The tissue healing process around anodized or acid etched implants, inserted in bone sites with and without defects, is quicker than in machined implants. Gurgel el al. (Gurgel et al., 2008) analyzed the efficiency of anodized implants. They used dog, and 3 months after teeth extraction, they produced defects measuring $5 \mathrm{~mm}$ high and $4 \mathrm{~mm}$ wide. After this they inserted the implants. The animals were sacrificed 3 months after the implant insertion. The researchers found that the percentages of bone-to-implant contact (BIC) and bone density (BD) of anodized implants were $57.03 \pm 21.86 \%$ and $40.86 \pm 22.73 \%$, whereas machined implants had $37.39 \pm 23.33 \%$ and $3.52 \pm 4.87 \%$, respectively.

Sul et al. (Sul et al., 2006) compared mechanical strength and osseous-conductivity of anodized implants containing magnesium, TiUnite ${ }^{\mathrm{TM}}$ (anodized) and Osseotite ${ }^{\mathrm{TM}}$ (double acid attack). The implants were inserted into rabbit tibia, and 3-6 weeks later removal torques and the percentage of bone-to-implant contact were measured. Figure 21 shows the experimental results. Magnesium implants demonstrated significantly greater removal torque values and more quantity of new bone formation than Osseotite ${ }^{\mathrm{TM}}$ at 3 and 6 weeks. Magnesium implants also showed higher removal torque values at 3 weeks and new bone formation at 6 weeks than TiUnite. The results indicate that surface chemistry facilitated more rapid and stronger osseointegration of the magnesium implants. This suggests potential advantages of magnesium implants for reducing high implant failure rates in the early post implantation stage and in compromised bone, making it possible to shorten bone healing time from surgery to functional loading, and enhancing the possibility of immediate/early loading.

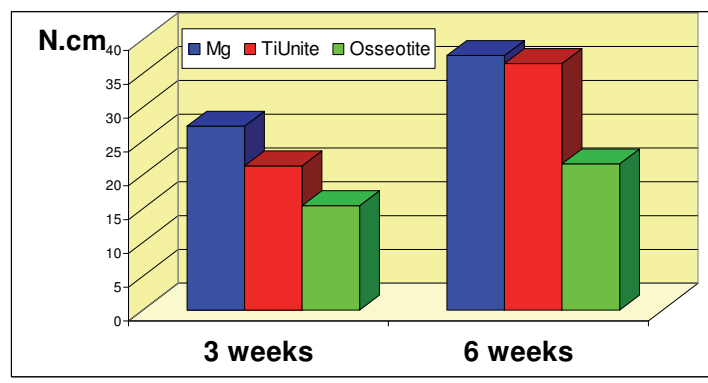

Fig. 21. Torque for removal (N.cm) and percentage of bone contact with implant surface $\mathrm{Mg}$, TiUnite $^{\mathrm{TM}}$ and Osseotite ${ }^{\mathrm{TM}}$. (Adapted from Sul et al. (Sul et al., 2006).

The anodized surface implant has a higher polarity compared with that of acid-treated samples, which causes adsorption of water and molecules. Adsorption of these molecules 
creates an electric field along the oxide thickness. This electric field induces titanium oxidation and, at the same time, the oxide layer thickness increases, thus decreasing both potential difference and the driving force for dissolution (Sul et al., 2006).

In this way, taking into account that surface structure as well as morphology are correlated with wettability, changes in their properties affect adsorption of proteins needed for cell adhesion on the implant surface. Consequently, the performance of a given treated surface depends on the biological response of the implants used.

Fröjd et al. (Fröjd et al., 20008) evaluated the bone response to an oxidized titanium implant (Ox) and a calcium-incorporated oxidized titanium implant (Ca). A blasted with $75 \mu \mathrm{m}$ Al2O3 particles titanium implant (Bl) was used as control. The implants were topographically characterized using an optical interferometer and placed: one in each distal femoral metaphysis and two in each proximal tibial metaphysis in rabbits. The rabbits were killed 12 weeks after implant insertion. Topographical evaluation revealed three different surfaces: average height deviation $(\mathrm{Sa}, \mu \mathrm{m})$ values for $\mathrm{Ca}: \mathrm{Ox}: \mathrm{Bl}$ implants were 0.3:0.6:0.9, developed surface area ratios (\%) 17:44:31. The Ca implants had a significantly denser surface, as represented by the parameter Sds, with $208 \pm 24$ sumsummits $/ \mu \mathrm{m}^{2}$; the Ox implants had a mean value of $136 \pm 9$ sumsummits $/ \mu \mathrm{m}^{2}$ and the $\mathrm{Bl}$ implants $118 \pm 9$ sumsummits $/ \mu \mathrm{m}^{2}$. The core fluid retention index values were 1.33:1.33:1.38 in $\mathrm{Ca}$, $\mathrm{Ox}$ and $\mathrm{Bl}$ implant, respectivaly. The mean percentages of bone contact to the implants placed in the tibia (Ca:Ox:Bl) were 47:30:34 and to the implants placed in the femur (Ca:Ox) 32:20. The mean percentages of surrounding bone area for the implants placed in the tibia were 40:47:37 and for the implants placed in the femur 43:46. A significant increase in bone contact was found for smooth (Sa $<0.5 \mu \mathrm{m})$ but more densely peaked calcium-incorporated oxidized implants when compared to slightly rougher $(\mathrm{Sa}=0.5-1.0 \mu \mathrm{m})$ oxidized or blasted implants.

\subsection{Nanoroughness}

Yang et al. (Yang et al., 2009) produced through the electrochemical anodizing treatment a mixed nano/submicron-scale TiO2 network layer (lateral pore size: $20-160 \mathrm{~nm}$ ) on polished Ti surface. Results showed that a nano/submicron-scale TiO2 network layer with a lateral pore size of $20-160 \mathrm{~nm}$ could be rapidly produced on Ti surface through electrochemical anodizing treatment. This $\mathrm{TiO} 2$ network layer significantly enhanced the whole blood coagulation and human bone marrow stem cell .

Webster et al. evaluated osteoblast adhesion in vitro on alumina and titania discs prepared by compacting powders with different sized particles onto the surface (Webster et al., 1999). The discs were sintered at different temperatures to obtain different nanoroughness parameters. Higher osteoblast adhesion was observed on both alumina and titania discs with increased mean root square deviation $(\mathrm{Sq})$ and larger surface area. Additionally, discs prepared with an identical method consisting of Ti, Ti6Al4 and CoCrMo was tested. As previously reported on alumina and titania discs, increased osteoblast adhesion was found on the discs from the different groups with increased mean root square deviation (Webster \& Ejiorf, 2004). Webster et al. investigated osteoblast adhesion and concentration of different proteins adsorbed on alumina, titania and HA, with different nanoroughnesses (Webster et al. 2000). Once again, the osteoblast adhesion was greater on the discs that exhibited increased nanoroughness, independently of the surface chemistry. Protein adsorption revealed a greater amount of vitronectin associated with increased osteoblast adhesion on the rougher discs. Osteoblast proliferation and alkaline phosphatase synthesis on these 
surfaces was evaluated in another study from the same group; alkaline phosphatase synthesis was higher after 21 and 28 days on the discs with increased nanoroughness values. De Oliveira and Nanci (Oliveira \& Nanci, 2004) cultured bone rat calvaria cells on titanium discs etched with $\mathrm{H} 2 \mathrm{SO} 4$ and $\mathrm{H} 2 \mathrm{O} 2$. They observed that the acid-etched surface revealed nanopits, whereas the control failed to show such features, although the surface roughness was not numerically evaluated. The results indicated an overexpression of osteopontin and bone sialoprotein, both intra- and extra-cellularly, on cells seeded on the nano-modified group. In addition, a higher proportion of cells with peripheral cytoplasmic distribution of osteopontin were observed as early as $6 \mathrm{~h}$.

Larlsson et al. evaluated turned plus anodized, electropolished, and electropolished plus anodized implants on a rabbit model after 1-6 weeks (Larsson et al., 1996). After 6 weeks, the electropolished implants showed decreased bone formation compared with the rougher implants. In an identical study, similar implants were investigated after 7-12 weeks of healing (Larsson et al., 1994 After 7 weeks, the results were similar to the previous study, which indicated higher bone formation to implants with increased surface roughness values (anodized) compared with the smooth implants (electropolished). After 12 weeks, the values for the rough implants were steady and the values for the electropolished implants increased to approximately the same level as that found for the rougher implants. Longterm evaluation of these implants for 1 year did not reveal any difference in bone formation (Larsson et al., 1997). It is concluded by in vitro and in vivo experiments that cell activity and bone healing may be optimized by modulating surface roughness on the nanometer level of resolution.

\section{Conclusion}

The success in implant dentistry depends on several parameters that may improve considering both biologic and mechanical criteria. Given below are some conclusions which show factors affecting the success of dental implants treatment.

- Although titanium is used extensively as a biomaterial, there are still doubts about the procedure to obtain the best biological response. Special relevance is the study of commercially pure titanium dental implant osseointegration.

- The strategy to improve dental implant osseointegration is to alter the biocompatibility of titanium implant surfaces, modifying the surgical technique and changing the implant design.

- The study of the interaction of cells with implant surface is a field of high topical interest and the detailed knowledge of these interactions can be used as the basis for the development of new surface treatments.

- Topographic characteristics, roughness, energy, and chemical composition modify cell growth and change cell function at the initial stages of osseointegration.

- Numerous surface modification approaches have been developed in order to improve commercially pure titanium dental implant osseointegration, to increase the primary stability and, in order to shorten the healing time.

- The surface properties of implants such as morphology, roughness, thickness of the oxide layer, chemical composition, impurity level and types of oxides depend on the surface treatment process. 
- The titanium dental implant surface morphology was modified by chemical and electrochemical treatment. Most of these surfaces have been analyzed by in vivo and in vitro studies, showing that the surface characteristics of the dental implants influence cell activity, which modifies the differentiation, proliferation, differentiation, and formation of extracellular matrix.

- The results show that the acid etching, sandblasting and electrochemical implant surface treatments are better than plasma spray or laser treatment. But, there is not a consensus among researchers as to the best surface and even the shape of the implants.

- The dental implant primary stability depends on the shape and surface morphology. The secondary stability depends mainly on the implant surface. The torque to install a conical implant is larger than the torque to install a cylindrical implant.

- The implants submitted to a surface treatment have a higher roughness, higher friction coefficient and higher primary stability than the machined one.

- There is need for research to improve the description of the interaction of cells with the implant surfaces, as well as analysis of the influence of different parameters in the interaction with proteins, stimulation of bone formation, use of individualized therapy and able to submit response differentiated for patients considered critical.

\section{Acknowledgments}

This manuscript has been supported by grants, here gratefully acknowledged, from Brazilian Government Research Foundation (CNPq under the 472449/2004-4, 400603/20047, 500126/2003 and 6306343/2006-1 project and FAPERJ E_26/102.714/2008 project).

\section{References}

Albrektsson T, Brånemark PI, Hansson HA, and Jonsson U. Ultrastructural analysis of the interface zone of titanium and gold implants, in Clinical Applications of Biomaterials (Eds Lee AJC, Albrektsson T and Brånemark P.-1.), John Wiley, New York, USA, 1982. pp 167-1 77 Plenk. H. Pfklger, G. and Bohler. ISBN 0-86715-129-3.

Albrektsson T, Brånemark PI, Hansson, HA \& Lindström J. (1981). Osseointegrated titanium implants. Acta Orthopaedica Scandinavica, 52, pp.155-179, ISSN 0001-6470.

Anitua E, Carda C, Andia I. (2007). A Novel Drilling Procedure and Subsequent Bone Autograft Preparation: A Technical Note. International Journal of Oral Maxillofacial Implants. Vol.22, pp.138-145, ISSN 0882-2786.

Anselme K, Bigerelle M. (2005). Topography effects of pure titanium substrates on human osteoblast long-term adhesion. Acta Biomaterialia. Vol.1, pp.211-222, ISSN 17427061.

Anselme K. (2000). Osteoblast adhesion on biomaterials. Biomaterials. Vol.21, pp.667-681, ISNN 0142-9612.

Askeland DR. (2006). The Science and Engineering of Materials. PWS-Kent Publishing Co, Canada.

Baier RE, Meyer AE. (1988). Implant surface preparation. International Journal of Maxillofacial Implants. Vol.3, pp.9-20, ISSN 0882-2786. 
Beer A, Gahleitner A, Holm A, Tschabitscher M, Homolka P. (2003). Correlation of insertion torques with bone mineral density from dental quantitative CT in the mandible. Clinical Oral Impl. Research. Vol.14, pp.616-620, ISSN 0905-7161.

Berglundh T, Abrahamsson I, Albouy J-P, Lindhe J. (2007). Bone healing at implants with a fluoride-modified surface: an experimental study in dogs. Clinical Oral Impant Research. Vol.18, pp.147-152, ISSN 0905-7161.

Biesbrock AR, Edgerton M. Evaluation of the clinical predictability of hydroxyapatite-coated endosseous dental implants: a review of the literature. International Journal of Oral Maxillofacial Implants. 1995 Nov-Dec;10(6):712-20

Binon PP. (1998). Evaluation of the effectiveness of a technique to prevent screw loosening. The Journal of Prosthetic Dentistry Vol. 79, pp. 430-432, ISSN0022-3913.

Bogaerde LV, Pedretti G, Sennerby L, Meredith N. (2010). Immediate/Early Function of Neoss Implants Placed in Maxillas and Posterior Mandibles: An 18-Month Prospective Case Series Study. Clinical Implant Dentistry and Related Research. Vol.12, pp.83-94, ISSN 1523-0899.

Boyan BD et all. (2001). The titanium-bone cell interface in vitro: the role of structure of the surface in promoting osseointegration. In, Donald M Brunnette, Penti Tengvall, Marcus Textor, Peter Thomsen. Titanium in medicine. Springer-Verlag 2001. p564.

Braceras I, De Maeztu MA, Alava JI, Gay-Escoda C. (2009). In vivo low-density bone apposition on different implant surface materials. International Journal of Oral Maxillofacial Surgery. Vol.38, pp. 274-278, ISSN 0901-5027.

Branemark PI, Breine U, Johansson B, Roylance PJ. (1964). Regeneration on bone marrow. Acta Anatomica. Vol.59, pp.1-46, ISSN 0001-5180.

Brunette DM. (2001). Principles of cells behaviour on Ti surfaces. In: Brunette, et al. (Eds.), Titanium in Medicine. SpringerVerlag, Berlin, p.485.

Busquim TP, Elias CN, May JE, Kuri SE, Nascente PAP. (2009) Titanium Oxide Layer on the Surface of Anodized Dental Implants. In Medical Device Materials V; Proceedings from the Materials \& Processes for Medical Devices Conference 2009 August 10-12, 2009, Minneapolis, Minnesota, USA, J. Gilbert, Ed., pp.60-65. ASM International, Metals Park, OH, USA. ISBN-13:978-1-61303-038-5.

Cho S-A and Jung S-K. (2003). A removal torque of the laser-treated titanium implants in rabbit tibia. Biomaterials.Vol. 24, pp. 4859-4863, ISSN 0142-9612.

Cochran DL, Schenk RK, Lussi A, Higginbottom FL, Buser D. (1998). Bone response to unloaded and loaded titanium implants with a sandblasted and acid-etched surface: a histometric study in the canine mandible. Journal of Biomedical Material Research. Vol.40, pp.1-11, ISSN 0021-9304.

Cooper LF, Zhou Y, Takebea J, Guo J, Abron A, Holme'n A, Ellingsen JE. (2006). Fluoride modification effects on osteoblast behavior and bone formation at TiO2 grit-blasted c.p. titanium endosseous implants. Biomaterials. Vol.27, pp.926-936, ISSN 0142-9612.

Cooper LF. (2003). Cellular interactions at cp Ti implants. In, Bio-implant interface. Improving biomaterials and tissue reactions. Jan Eirik Ellingsen and S. Petter Lyngstadaas. CRC Press 2003. pp.165-181. 
Cordioli G, MajzoubZ, Piatelli A, Scarano A. (2000). Removal torque and histomorphometric investigation of 4 different titanium surfaces. International Journal of Oral Maxillofacial Implants. Vol.15, pp.668-74, ISSN 0882-2786.

Dee KC, Puleo DA, Bizios R. (2002a). An introduction to tissue-biomaterials interactions. John Wiley \& Sons. p.192, ISBN: 978-0-471-25394-5.

Dee KC, Puleo DA, Bizios R. (2002b). An introduction to tissue-biomaterials interactions. John Wiley \& Sons. p.49, ISBN: 978-0-471-25394-5.

Elias CN, Meirelles L. (2010). Improving osseointegration of dental implants. Expert Review Medical Devices. Vol.7, pp.241-256, ISSN 1743-4440.

Elias CN, Oshida Y, Limad JHC, Muller CA. (2008). Relationship between surface properties, roughness, wettability and morphology) of titanium and dental implant removal torque. Journal of Mechanical Behavior of Biomedical Materials. Vol.1, pp.234242, ISSN 1751-6161.

Ellingsen JE, Johansson CB, Wennerberg A, Holmen A. (2004). Improved retention and bone to implant contact with fluoride modified titanium implants. International Journal of Oral Maxillofacial Implants. Vol.19, pp.659-666, ISSN 0882-2786.

Ellingsen JE. (1995). Pre-treatment of titanium implants with fluoride improves their retention in bone. Journal of Materials Science: Materials in Medicine. Vol.6, pp.749753, ISSN 0957-4530.

Eriksson C, Lausmaa J, Nygren, H. (2001). Interactions between human whole blood and modified Ti-O2-surfaces: Influence of surface topography and titanium oxide thickness on leukocyte adhesion and activation. Biomaterials. Vol.22, pp.1987-1996, ISNN 0142-9612.

Faeda RS, Tavares HS, Sartori R, Guastaldi AC, Marcantonio E Jr. (2009). Biological performance of chemical hydroxyapatite coating associated with implant surface modification by laser beam: biomechanical study in rabbit tibias. International Journal of Oral Maxillofacial Surgery. Vol.67, pp.1706-1715, ISSN 0901-5027.

Feng B, Weng J, Yang BC, Qu SX, Zhang XD. (2004). Characterization of titanium surfaces with calcium and phosphate and osteoblast adhesion. Biomaterials. Vol.25, pp.34213428, ISNN 0142-9612.

Fröjd V, Franke-Stenport V, Meirelles L, Wennerberg A. (2008). Increased bone contact to a calcium-incorporated oxidized commercially pure titanium implant: an in-vivo study in rabbits. International Journal of Oral Maxillofacial Surgery. Vol.37, pp.561566, ISSN 0901-5027.

Gaggl A, Schultes G, Muller WD, Karcher H. (2000). Scanning electron microscopical analysis of laser-treated titanium implants surfaces-a comparative study. Biomaterials. Vol.21, pp.1067-1073, ISSN 0142-9612.

Gurgel BC, Gonçalves PF, Pimentel SP, Nociti FH, Sallum EA, Sallum AW, Casati MZ. (2008). An oxidized implant surface may improve bone-to-implant contact in pristine bone and bone defects treated with guided bone regeneration: an experimental study in dogs. Journal of Periodontology. Vol.79, pp.1225-1231, ISSN 0022-3492. 
Hayakawa T, Yoshinari M, Nemoto K, Wolke JGC, Jansen JA. (2000). Effect of surface roughness and calcium phosphate coating on the implant/bone response. Clinical Oral Implant Research. Vol. (11): 296-304, ISSN 0905-7161.

Hennessy KM, Pollot BE, Clem WC, Phipps MC, Sawyer AA, Culpepper BK, Bellis SL. (2009). The effect of collagen I mimetic peptides on mesenchymal stem cell adhesion and differentiation, and on bone formation at hydroxyapatite surfaces. Biomaterials. Vol.30, pp.1898-1909, ISSN 0142-9612.

Jarmar T, Palmquist A, Brånemark R, Hermansson L, Engqvist H, Thomsen P. (2008). Characterization of the surface properties of commercially available dental implants using scanning electron microscopy, focused ion beam, and highresolution transmission electron microscopy. Clinical Implant Dentistry Related Research. Vol.10, pp.11-22, ISSN 1523-0899.

Javed F, Almas K, Crespi R, Romanos GE. (2011). Implant Surface Morphology and Primary Stability: Is There a Connection? Implant Dentistry. Vol. 20, pp. (1) 2011 40-46, ISSN 1056-6163.

Javed F, Romanos GE. (2010). The role of primary stability for successful immediate loading of dental implants. A literature review. Journal of Dentistry. Vol.38, pp.612-620, ISSN 0300-5712.

Jayaraman M, Meyer U, Buhner M, Joos U, Wiesmann HP. (2004). Influence of titanium surfaces on attachment of osteoblast-like cells in vitro. Biomaterials. Vol.25, pp.625631, ISSN 0142-9612.

Johansson CB, Hamson BA and Albrektsson T. (1990) Quantive interfacial study bone and tantalum, niobium commerciallyp ure titanium. Biomaterials. Vol. 11, pp.277-280. ISSN 0142-9612

Kashiwagi K, Tsuji T, Shiba K. (2009). Directional BMP-2 for functionalization of titanium surfaces. Biomaterials. Vol.30, pp.1166-1175, ISSN 0142-9612.

Kikuchia L, Park JY, Victor C, Davies JE. (2005). Platelet interactions with calciumphosphate-coated surfaces. Biomaterials. Vol.26, pp.5285-5295, ISSN 0142-9612.

Kokubo T, Kim HM, Kawashita M, Nakamura T. (1999). What kids of materials exhibit bone-bonding? In JE Davies. Bone Engineering . Em Squared Incorporated, Toronto, Canada, pp.190-194.

Larsson C, Thomsen P, Aronsson B-O, Rodahl M, Lausmaa J, Kasemo B, Ericson LE.(1996). Bone response to surface-modified titanium implants: studies on the early tissue response to machined and electropolished implants with different oxide thicknesses. Biomaterials. Vol.17, pp.605-616, ISSN 0142-9612.

Larsson C, Emanuelsson L, Thomsen P et al. (1997). Bone response to surface modified titanium implants - studies on the tissue response after 1 year to machined and electropolished implants with different oxide thicknesses. Jornal of Materials Science: Materials in Medicine. Vol.8, pp.721-729, ISSN 0957-4530.

Larsson C, Thomsen P, Lausmaa J, Rodahl M, Kasemo B, Ericson LE. (1994). Bone response to surface modified titanium implants: studies on electropolished implants with different oxide thicknesses and morphology. Biomaterials. Vol.15, pp.1062-1074, ISSN 0142-9612. 
Le Duc P, Wang Y. (2006).Protein adsortion at biomaterial-tissue interface. In An Introduction to Biomaterials, Edited Guelcher SA and Hollinger JO. Biomedical Materials Series. CRC Taylor \&Francis Group 2006, p47.

Lekholm O, Zarb GA. (1985). Patient selection and preparation. In:Branemark PI et al. Editors: Tissue integrated prostheses - Osseointegration in clinical dentistry. Chicago, Quintessence, pp.199-209.

Li Y, Lee IS, Cui FZ, Choi SH. (2008). The biocompatibility of nanostructured calcium phosphate coated on micro-arc oxidized titanium. Biomaterials. Vol.29, pp.20252032, ISSN 0142-9612.

Lim JY, Liu X, Vogler EA, Donahue HJ. (2004). Systematic variation in osteoblast adhesion and phenotype with substratum surface characteristics. Jorurnal of Biomedical Materials Research. Vol.68A, pp.504-512, ISSN 1549-3296.

Lim YJ, Oshida Y, Andres CJ, Barco MT. (2001). Surface characterizations of variously treated titanium materials. International Journal of Oral Maxillofacial Implants. Vol.16, pp.333-342, ISSN 0882-2786.

Lincks J, Boyan BD, Blanchard CR, Lohmann CH, Liu Y, Cochran DL, Dean DD, Schwartz Z. (1998). Response of MG63 osteoblastlike cells to titanium and titanium alloy is dependent on surface roughness and composition. Biomaterials. Vol.19, pp.22192232, ISSN 0142-9612.

Menezes GC, Elias CN, Attias M, Silva-Filho FC. (2003). Osteoblast Adhesion onto Titanium Dental Implants. Acta Microscopica. Vol.12, pp.13-19, ISSN 1728-5917.

Misch CE. (2008). Contemporary implant dentistry. Mosby - St Louis 2008. 0801660734.

Morais LS, Serra GG, Palermo EFA, Andrade LR, Muller CA, Meyers MC, Elias CN. (2009). Systemic levels of metallic ions released from orthodontic mini-implants. American Journal Orthodontics Dentofacial Orthopedics. Vol.135, pp.:522-529. ISSN 0889-5406

Morton RK. Topography of Surfaces. (1994). In: ASM Handbook. Surface Engineering. Vol.5, ASM, Materials Park, OH, pp.136-138.

Nayab SN, Jones FH, Olsen I. (2005). Effects of calcium ion implantation on human bone cell interaction with titanium. Biomaterials. Vol.26, pp.4717-4727, ISSN 0142-9612.

Niinomi M. (2002). Recent Metallic Materials for Biomedical Applications. Metallurgical and Materials Transaction A. Vol.33A, pp.477-486, ISSN 1073-5623.

Novak MT, Bryers JD, Reichert WM. (2009). Biomimetic strategies based on viruses and bacteria for the development of immune evasive biomaterials. Biomaterials. Vol.30, pp.1989-2005, ISSN 0142-9612.

Ohtsu N, Sato K, Saito K, Asami K, Hanawa T. (2007). Calcium phosphates formation on $\mathrm{CaTiO}(3)$ coated titanium. Journal of Materials Science: Materials in Medicine. Vol.18, pp.1009-1016, ISSN 0957-4530.

Oliveira PT, Nanci A. (2004). Nanotexturing of titanium-based surfaces upregulates expression of bone sialoprotein and osteopontin by cultured osteogenic cells. Biomaterials. Vol.25, pp.403-413, ISNN 0142-9612.

Ong JL, andChan DCN. (2000). Hydroxyapatite and their use as coatings in dental implants: a review. Critical Review in Biomedical Engineering. Vol 28, pp.235-239. ISSN: 0278940X. 
Oshida Y, Tuna EB, Aktören O, Gençay K. (2010). Dental Implant Systems. International Journal of Molecules Science. Vol.11, pp.1580-1678, ISSN 1422-0067.

Owens DK and Wendt RC. (1969). Estimation of the surface free energy of polymers. Journal of Applied Polymer Science. Vol.13, pp1741-1747. ISSN 1097-4628.

Puleo DA, Bizios R. (1992). Mechanisms of fibronectin mediated attachment of osteoblasts to substrats in vitro. Journal of Bone and Mineral Research. Vol.18, pp.215-226, ISSN 0169-6009.

Richards RG. (1996). The effect of surface roughness on fibroblast adhesion in vitro. Injury. Vol.27, pp.S-C38-S-C43, ISSN 0020-1383.

Romanos GE, Toh CG, Siar CH, Swaminathan D. (2002). Histologic and histomorphometric evaluation of peri-implant bone subjected to immediate loading: an experimental study with Macaca fascicularis. International Journal of Oral and Maxillofacial Implants. Vol.17, pp.44-51, ISSN 0882-2786.

Santos MV, Elias CN, Cavalcanti Lima JH. The effects of superficial roughness and design on the primary stability of dental implants. Clinical Implant Dental Related Research. In press

Schuckert KH, Jopp S, Muller U. (2006). De Novo Grown Bone on Exposed Implant Surfaces Using Photodynamic Therapy and Recombinant Human Bone Morphogenetic Protein-2: Case Report Implant Dentistry. Vol.15, pp.361-365, ISSN 1056-6163.

Sener BC, Dergin G, Gursoy B, Kelesoglu E, Slih I. (2009). Effects of irrigation temperature on heat control in vitro at different drilling depths. Clinical Oral Implant Research. Vol.20, pp.294-298, ISSN ISSN 0905-7161.

Soballe K, Hansen ES, Brockstedt-Rasmussen H, Bunger C. (1993). Hydroxyapatite coating converts fibrous tissue to bone around loaded implants. Journal of Bone and Joint Surgery Br. Vol.75, pp.270-278, ISSN 0301-620X.

Stadlinger B, Pilling E, Huhle M, Mai R, Bierbaum S, Scharnweber D, Kuhlisch E, Loukota R, Eckelt U. (2008). Evaluation of osseointegration of dental implants coated with collagen, chondroitin sulphate and BMP-4: an animal study. International Journal of Oral Maxillofacial Surgery. Vol.37, pp.54-59, ISSN 0901-5027.

Sul YT, Johansson C, Albrektsson T. (2006). Which surface properties enhance bone response to implants? Comparison of oxidized magnesium, TiUnite, and Osseotite implant surfaces. International Journal of Prosthodontics. Vol.19, pp.319-328, ISSN 0893-2174.

Sun L, Berndt CC, Gross KA, Kucuk A. (2001). Material fundamentals and clinical performance of plasma-sprayed hydroxyapatite coatings: a review. Journal of Biomedical Materials Research. Vol.58, pp.570-592, ISSN 1549-3296.

Suzuki M, Guimaraes MV, Marin C, Granato R, Gil JN, Coelho PG. (2009). Histomorphometric Evaluation of Alumina-Blasted/Acid-Etched and Thin Ion Beam-Deposited Bioceramic Surfaces: An Experimental Study in Dogs. International Journal of Oral Maxillofacial Surgery. Vol.67, pp.602-607, ISSN 0278-2391.

Szmukler-Moncler S, Piattelli A, Favero GA, Dubruille JH. (2000). Considerations preliminary to the application of early and immediate loading protocols in dental implantology. Clinical Oral Implants Research. Vol.11, pp.12-25, ISSN 0905-7161.

Tang $\mathrm{L}$ and $\mathrm{Hu}$ W. (2005). Molecular determinants of biocompatibility. Expert Review Medical Devices. Vol. 2, pp.493-500, ISSN 1743-4440. 
Tete S, Mastrangelo F, Traini T, Vinci R, Sammartino G, Marenzi G, Gherlone E. (2008). A Macro and Nanostructure Evaluation of a Novel Dental Implant. Implant Dentistry. Vol.17, pp.309-320, ISSN 1056-6163.

Thull R. (2002). Physicochemical principles of tissue material interactions. Biomolecular Engineering. Vol.19, pp.43-50, ISSN 1389-0344.

Vladkova TG. (2010). Surface Engineered Polymeric Biomaterials with Improved Biocontact Properties. International Journal of Polymer Science. Vol.2010, Article ID 296094, 22 pages, ISSN 1687-9422.

Togashi AY, Cirano FR, Lima LAPA. (2007). The role of implant surface chemistry in the biological bone response. RPG Revista Pos Graduação. Vol.13, pp.340-344.

Webster TJ, Ejiofor JU. (2004). Increased osteoblast adhesion on nanophase metals: Ti, Ti6Al4V, and CoCrMo. Biomaterials. Vol. 25, pp.4731-4739, ISSN 0142-9612.

Webster TJ, Ergun C, Doremus RH, Siegel RW, Bizios R. (2000). Enhanced functions of osteoblasts on nanophase ceramics. Biomaterials. Vol.21, pp.1803-1810, ISSN 01429612.

Webster TJ, Siegel RW, Bizios R. (1999). Osteoblast adhesion on nanophase ceramics. Biomaterials. Vol.20, pp.1221-1227, ISSN 0142-9612.

Wennerberg A, Albrektsson T, Andersson B. (1995). An animal study of cp titanium screws with different surface topographies. Journal of Materials Science: Materials in $M$ edicine. Vol.6, pp.302-309, ISSN 0957-4530.

Wennerberg A, Albrektsson T, Lindhe J. (2003). Surface topography of titanium implants. pp.821-828. In Jan Lindhe, Thorkild Karring and Niklaus P. Lang Editor. Clinical Periodontology and clinical dentistry. Fourth edition 2003. Blackwell Munksgaard, a Blackwell Publishing Company. ISBN: 1-4051-0236-5. Oxford, UK.

Wennerberg A, Hallgren C, Johansson C, Danelli S. (1998). A histomorphometric evaluation of screw-shaped implants each prepared with two surface roughnesses. Clinical Oral Implants Research. Vol.9, pp.11-19, ISSN 0905-7161.

Wennerberg A. (1998). The importance of surface roughness for implant incorporation. International Jornal of Machining and Tools Manufacturing. Vol.38, pp.657-662, ISSN 0890-6955.

Wennerberg A. On surface and implant incorporation. Ph.D. Thesis. Goteborg University 1996.

Werner S, Huck O, Frisch B, Vautier D, Elkaim R, Voegel JC, Brunel G Tenenbaum H. (2009). The effect of microstructured surfaces and laminin-derived peptide coatings on soft tissue interactions with titanium dental implants. Biomaterials. Vol.30, pp.2291-2301, ISSN 0142-9612.

Verrier S, Pallu S, Bareille R, Jonczyk A, Meyer J, Dard M, Amédée J. (2002). Function of linear and cyclic RGD-containing peptides in osteoprogenitor cells adhesion process. Biomaterials. Vol.23, pp.585-596, ISSN 0142-9612.

Williams DF. (2008). On the mechanisms of biocompatibility. Biomaterials. Vol.29, pp. 29412953, ISSN 0142-9612.

Williams DF. Titanium and titanium alloys. In: Williams DF, editor. Biocompatibility of clinical implant materials, vol. I. Boca Raton, Florida: CRC Press, Inc.; 1981. p. 9-44. 
Wolner C, Nauer GE, Trummer J, Putz V, Tschegg S. (2006). Possible reasons for the unexpected bad biocompatibility of metal-on-metal hip implants. Materials Science and Engineering C. Vol.26, pp.34-40, ISSN 0928-4931.

Yang W-E, Hsu M-L, Lin M-C, Chen Z-H, Chen L-K, Huang H-H. (2009). Nano/submicronscale $\mathrm{TiO} 2$ network on titanium surface for dental implant application. Journal of Alloys and Compounds. Vol.479, pp.642-647, ISSN 0925-8388.

Zhu X, Chen J, Scheideler L, Reichl R, Geis-Gerstorfer J. (2004). Effects of topography and composition of titanium surface oxides on osteoblast responses. Biomaterials. Vol.25, pp.4087-4103, ISSN 0142-9612. 


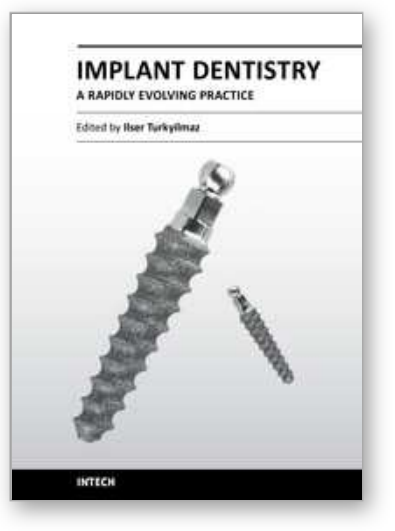

\author{
Implant Dentistry - A Rapidly Evolving Practice \\ Edited by Prof. Ilser Turkyilmaz
}

ISBN 978-953-307-658-4

Hard cover, 544 pages

Publisher InTech

Published online 29, August, 2011

Published in print edition August, 2011

Implant dentistry has come a long way since Dr. Branemark introduced the osseointegration concept with endosseous implants. The use of dental implants has increased exponentially in the last three decades. As implant treatment became more predictable, the benefits of therapy became evident. The demand for dental implants has fueled a rapid expansion of the market. Presently, general dentists and a variety of specialists offer implants as a solution to partial and complete edentulism. Implant dentistry continues to evolve and expand with the development of new surgical and prosthodontic techniques. The aim of Implant Dentistry - A Rapidly Evolving Practice, is to provide a comtemporary clinic resource for dentists who want to replace missing teeth with dental implants. It is a text that relates one chapter to every other chapter and integrates common threads among science, clinical experience and future concepts. This book consists of 23 chapters divided into five sections. We believe that, Implant Dentistry: A Rapidly Evolving Practice, will be a valuable source for dental students, post-graduate residents, general dentists and specialists who want to know more about dental implants.

\title{
How to reference
}

In order to correctly reference this scholarly work, feel free to copy and paste the following:

Carlos Nelson Elias (2011). Factors Affecting the Success of Dental Implants, Implant Dentistry - A Rapidly Evolving Practice, Prof. Ilser Turkyilmaz (Ed.), ISBN: 978-953-307-658-4, InTech, Available from: http://www.intechopen.com/books/implant-dentistry-a-rapidly-evolving-practice/factors-affecting-the-successof-dental-implants

\section{INTECH}

open science | open minds

\section{InTech Europe}

University Campus STeP Ri

Slavka Krautzeka 83/A

51000 Rijeka, Croatia

Phone: +385 (51) 770447

Fax: +385 (51) 686166

www.intechopen.com

\section{InTech China}

Unit 405, Office Block, Hotel Equatorial Shanghai

No.65, Yan An Road (West), Shanghai, 200040, China 中国上海市延安西路65号上海国际贵都大饭店办公楼405单元

Phone: +86-21-62489820

Fax: +86-21-62489821 
(C) 2011 The Author(s). Licensee IntechOpen. This chapter is distributed under the terms of the Creative Commons Attribution-NonCommercialShareAlike-3.0 License, which permits use, distribution and reproduction for non-commercial purposes, provided the original is properly cited and derivative works building on this content are distributed under the same license. 